\title{
Resveratrol protects retinal ganglion cells against ischemia induced damage by increasing Opa1 expression
}

\author{
YULIAN PANG ${ }^{*}$, MENGQI QIN*, PIAOPIAO HU, KAIBAO JI, RUIHAN XIAO, \\ NAN SUN, XINGHUI PAN and XU ZHANG

\begin{abstract}
Affiliated Eye Hospital of Nanchang University, Jiangxi Research Institute of Ophthalmology and Visual Science, Jiangxi Provincial Key Laboratory for Ophthalmology, Nanchang, Jiangxi 330006, P.R. China
\end{abstract}

Received March 5, 2020; Accepted July 27, 2020

DOI: $10.3892 /$ ijmm.2020.4711

\begin{abstract}
Loss of idiopathic retinal ganglion cells (RGCs) leads to irreversible vision defects and is considered the primary characteristic of glaucoma. However, effective treatment strategies in terms of RGC neuroprotection remain elusive. In the present study, the protective effects of resveratrol on RGC apoptosis, and the mechanisms underlying its effects were investigated, with a particular emphasis on the function of optic atrophy 1 (Opa1). In an ischemia/reperfusion (I/R) injury model, the notable thinning of the retina, significant apoptosis of RGCs, reduction in Opal expression and long Opal isoform to short Opal isoform ratios (L-Opa1/S-Opa1 ratio) were observed, all of which were reversed by resveratrol administration. Serum deprivation resulted in reductions in R28 cell viability, superoxide dismutase (SOD) activity, Opa1 expression and induced apoptosis, which were also partially reversed by resveratrol treatment. To conclude, results from the present study suggest that resveratrol treatment significantly reduced retinal damage and RGC apoptosis in I/R injury and serum deprivation models. In addition, resveratrol reversed the downregulated expression of Opal and reduced SOD activity. Mechanistically, resveratrol influenced mitochondrial dynamics by regulating the L-Opa1/S-Opa1 ratio. Therefore, these observations suggest that resveratrol may exhibit potential as a therapeutic agent for RGC damage in the future.
\end{abstract}

\section{Introduction}

Glaucoma describes a group of eye diseases that are characterized by idiopathic optic nerve injury and is regarded as

Correspondence to: Professor Xu Zhang, Affiliated Eye Hospital of Nanchang University, Jiangxi Research Institute of Ophthalmology and Visual Science, Jiangxi Provincial Key Laboratory for Ophthalmology, 463 Bayi Road, Nanchang, Jiangxi 330006, P.R. China

E-mail: xuzhang19@163.com

${ }^{*}$ Contributed equally

Key words: retinal ganglion cells, resveratrol, optic atrophy 1, sirtuin1, neuroprotection the primary cause of irreversible visual impairment (1). It is generally accepted that the abnormal elevation of intraocular pressure (IOP), which is one of the critical risk factors associated with retinal ganglion cell (RGC) damage, is primarily responsible for the occurrence and development of glaucoma (2). However, since RGC failure is also observed under normal IOP, and appropriate IOP control can only inhibit RGC degeneration induced by ocular hypertension (3), novel neuroprotective approaches for RGCs are required as an additional strategy in managing glaucoma.

There are several hypotheses into the possible mechanisms underlying RGC cell death in glaucoma, including oxidative stress, glutamate excitotoxicity and nitric oxide-induced injury (4). In addition, accumulating evidence is suggesting that mitochondrial dysfunction can also result in the death of RGCs (5-7). Mitochondria are subcellular organelles that are enclosed in two layers of separated membranes and are considered a cornerstone of metabolism in the cell by generating energy (8). Therefore, mitochondrial dysfunction induces detrimental effects on cells, particularly those with higher energy demands, including RGCs, cardiomyocytes and skeletal muscle cells (9-12). Mitochondria continuously undergo morphological changes. This dynamic process, which is caused by the constant cycle of fusion and fission, is under strict sophisticated regulation by a group of dynamin-related GTPases $(13,14)$. Among these mitochondrial dynamins, optical atrophy 1 (Opa1) is of particular interest. Opa1 is a mitochondrial protein that is encoded in the nucleus, which can not only regulate mitochondrial fusion but can also inhibit programmed cell death by regulating cytochrome $\mathrm{c}$ release (15).

Trans 3,5,4'-trihydroxystilbene, commonly referred to as resveratrol, is an important activator of sirtuin1 (Sirt1) that is abundantly present in giant knotweed, wine and grapes $(16,17)$. Over recent decades, resveratrol has been garnering significant research attention due to its numerous potentially beneficial properties being reported, including anti-apoptotic, anti-inflammatory and antioxidant $(18,19)$. Additionally, no apparent adverse effects of resveratrol treatment have been observed in previous animal models and clinical human studies, suggesting that resveratrol has promising prospects for future therapeutic use (20). Previous studies in rat models of glaucoma have also shown that resveratrol can exert protective 
effects on RGCs (21). However, the precise mechanisms of the effects of resveratrol on RGCs have not been fully characterized (22).

The present study investigated the potential effects of resveratrol on ischemia/reperfusion (I/R)-induced retina injury and serum deprivation-induced $\mathrm{R} 28$ cell apoptosis. The results showed that resveratrol protected RGCs against apoptosis by regulating the expression of Opal and the activity of superoxide dismutase (SOD). Additionally, it was found that resveratrol influenced the long Opa1 isoform to short Opa1 isoform (L-Opa1/S-Opa1) ratio by regulating the expression of proteins that post-translationally process Opa1 in the retina, including overlapping activity with m-AAA protease (Oma1) and yeast mitochondrial DNA escape 1 (Yme1). Although further study may be warranted to confirm the relationship between resveratrol and post-transcriptional proteases of Opal, the present study contributes evidence that resveratrol can exert protective effects on RGCs.

\section{Materials and methods}

Animals. All experiments concerning animal studies were performed in accordance with the Association for Research in Vision and Ophthalmology Statement for the Use of Animals in Ophthalmic and Vision Research (arvo. org/About/policies/statement-for-the-use-of-animals-in-ophtha lmic-and-vision-research/). All procedures concerning animal use were approved and monitored by the Institutional Animal Care and Use Committee of Nanchang University (approval no. 2016NC-020-02). Male Sprague-Dawley (SD) rats, 2-3 months of age were provided by the Center of Laboratory Animal Science of Nanchang University and were used for transient retinal I/R studies. The rats were provided free access to sterile water and food and housed in a controlled environment with a $12-\mathrm{h} \mathrm{light} / \mathrm{dark}$ cycle at $23^{\circ} \mathrm{C}$ and $60 \%$ humidity.

$R 28$ cell culture. All reagents required for cell culture were provided by Biological Industries. R28 retinal neuronal-like cells were kindly provided by $\mathrm{Dr}$ Guotong Xu (Tongji University School of Medicine). R28 cells were maintained in low-glucose DMEM containing $100 \mathrm{mg} / \mathrm{ml}$ streptomycin, $100 \mathrm{U} / \mathrm{ml}$ penicillin and $10 \% \mathrm{FBS}$, in a humidified incubator with $5 \% \mathrm{CO}_{2}$ at $37^{\circ} \mathrm{C}$ as described previously (23). Cells were sub-cultured every 3-4 days, and they had a doubling time of 18-20 h.

Transient retinal I/R model. A total of 66 rats were randomly separated into four groups: i) Sham group ( $\mathrm{n}=18$, eyes/group); ii) $I / R$ group ( $n=30$, eyes/group); iii) $I / R+$ vehicle group $(n=18$, eyes/group); iv) and $\mathrm{I} / \mathrm{R}+$ resveratrol group ( $\mathrm{n}=18$ eyes/group). The right eye was used for the $I / R$ procedure in the $I / R$, $I / R+$ vehicle and $I / R+$ resveratrol groups. The sham procedure which cannulated and maintained the eye at normal IOP was performed on the left eye of the rats in the I/R group and was used as the control (24). To minimize the suffering of rats during I/R injury, rats were anesthetized by an intraperitoneal injection of $10 \%$ chloral hydrate $(400 \mathrm{mg} / \mathrm{kg})$ prior to $\mathrm{I} / \mathrm{R}$ injury and did not exhibit symptoms of discomfort, including pain or peritonitis following chloral hydrate administration. To induce ocular ischemia, the IOP was elevated $(\sim 110 \mathrm{~mm} \mathrm{Hg})$ in one eye of the rats by cannulating the anterior chambers through a canula equipped with a raised reservoir for $60 \mathrm{~min}$. Completion of retinal ischemia was judged by observing the blanching of the iris and retina. Resveratrol (Sigma-Aldrich; Merck KGaA) was dissolved and diluted in $25 \%$ ethanol to a concentration of $10 \mathrm{mg} / \mathrm{ml}$. The I/R + resveratrol group were injected intraperitoneally with $25 \mathrm{mg} / \mathrm{kg}$ resveratrol 1 day before, at the time of and 1 day after I/R retina injury, whilst the $\mathrm{I} / \mathrm{R}+$ vehicle group were treated with $25 \%$ ethanol. After 1,3 and 7 days of retinal ischemia, the rats were euthanized by an intraperitoneal injection of $2 \%$ sodium pentobarbital $(100 \mathrm{mg} / \mathrm{kg})$, and the heartbeat, breathing and corneal reflex were observed. After verification of animal death through a lack of heartbeat, breathing or respiration, the eyeballs were then harvested from each rat.

Serum deprivation and drug treatment. Retinal neuronal R28 cells were seeded at the desired density into tissue culture dishes. A total of 8 groups of cells, which were seeded into 6 -well plates at a density of $1.5 \times 10^{6}$ cells/well, were washed three times with PBS. For serum deprivation treatment, three groups of cells were incubated in serum-free DMEM for 12, 24 or $48 \mathrm{~h}$ respectively. Cells in the control group were incubated with supplemented DMEM. For resveratrol treatment studies, resveratrol was dissolved in DMSO to a stock concentration of $10 \mathrm{mM}$, and three groups of cells were then treated with $4 \mu \mathrm{M}$ resveratrol dissolved in serum-free DMEM for 12, 24 or $48 \mathrm{~h}$ (25). The cells were incubated with supplemented DMEM containing $4 \mu \mathrm{M} \mathrm{DMSO}$, and was considered the vehicle group. Untreated cells and treated cells were incubated in serum-free DMEM in the same manner as the normal controls and serum deprivation controls, respectively.

Protein preparation. Retinal tissue was separated from the retinal pigment epithelium and choroid before lysing using RIPA buffer containing PMSF (Beijing Solarbio Science \& Technology Co., Ltd.). The lysates were then centrifuged at $15,000 \times \mathrm{g}$ at $4^{\circ} \mathrm{C}$ for $15 \mathrm{~min}$, following which, the supernatant was collected to obtain tissue proteins.

For R28 cells, whole cell lysates were obtained by adding PMSF-containing RIPA buffer, followed by centrifugation at $10,000 \mathrm{xg}$ for $20 \mathrm{~min}$ at $4^{\circ} \mathrm{C}$. The supernatant, which contained the cellular proteins, was collected. The concentration of proteins were determined using a Bradford assay (Beyotime Institute of Biotechnology) according to the manufacturer's protocols.

Western blot analysis. The sample protein $(30 \mu \mathrm{g})$ was separated using 7.5-15\% SDS-PAGE and transferred onto a nitrocellulose membrane. Blots were blocked in 5\% non-fat dry milk in TBS/Tween-20 for $1 \mathrm{~h}$ at room temperature before incubation with the appropriate primary antibodies against Sirt1 (1:1,000; cat. no. 9475; Cell Signaling Technology, Inc.), Opa1 (1:1,000; cat. no. 612606; BD Biosciences) or $\beta$-tubulin (1:1,000; cat. no. HC101-01; TransGen Biotech) overnight at $4{ }^{\circ} \mathrm{C}$. The blots were then incubated with a horseradish peroxidase-conjugated anti-rabbit IgG secondary antibody (1:2,500; cat. no. 7074; Cell Signaling Technology, Inc.) or horseradish peroxidase-conjugated anti-mouse IgG secondary antibody (1:2,500; cat. no. 7076; Cell Signaling Technology, Inc.) for $1 \mathrm{~h}$ at room temperature. Finally, protein bands on the 
membrane were visualized using enhanced chemiluminescent western blot detection reagent (EMD Millipore). Densitometry analysis was performed using ImageJ version 1.46 (National Institutes of Health).

$R N A$ extraction and reverse transcription-quantitative $P C R$ $(R T-q P C R)$. According to the manufacturer's protocols, RNA was extracted from the rat retinas using TRIzol ${ }^{\circledR}$ reagent (Invitrogen; Thermo Fisher Scientific, Inc.). RNA concentration and purity were determined using spectrophotometry (Tiangen Biotech Co., Ltd.; cat. no. OSE-260). The extracted RNA (200 ng/sample) was then reverse-transcribed into cDNA using the Quantscript RT kit (Tiangen Biotech Co., Ltd.). Specific oligonucleotide primers for each gene, including Sirt1, Opa1, Oma1, Yme1 and $\beta$-actin (Table I), were designed and synthesized by Tiangen Biotech Co., Ltd.. Subsequently, qPCR was performed using RealMasterMix (SYBR Green) kit (Tiangen Biotech Co., Ltd.) with the following thermocycling conditions: $95^{\circ} \mathrm{C}$ for $20 \mathrm{sec}$; followed by 39 cycles of $58^{\circ} \mathrm{C}$ for $20 \mathrm{sec}$ and $68^{\circ} \mathrm{C}$ for $30 \mathrm{sec}$. All samples were tested in triplicate, and the mean of the reactions was used for calculating the expression levels. All the data were collected from the linear range of each amplification. The results obtained were analyzed using the $2^{-\Delta \Delta \mathrm{Cq}}$ method (26) and expression levels were normalized to the average of the $\beta$-tubulin mRNA levels from the same samples.

Immunocytochemistry. $\mathrm{R} 28$ cells cultured in dishes were fixed with PBS containing 4\% sucrose and $4 \%$ paraformaldehyde (PFA) for $20 \mathrm{~min}$ at room temperature. Cells were then blocked with PBS containing 5\% BSA and $0.2 \%$ Triton X-100 (PBSTX) for $30 \mathrm{~min}$ at room temperature. Cells were incubated at room temperature with primary antibodies against Opa1 (1:50) diluted in PBSTX with 1\% BSA for 4-6 h. The fixed cells were then washed and incubated with the appropriate Alexa Fluor ${ }^{\circledR}$ 488-conjugated donkey anti-Mouse $\operatorname{IgG}(\mathrm{H}+\mathrm{L})$ secondary antibody (1:200; cat. no. R37144; Thermo Fisher Scientific, Inc.) dissolved in PBSTX containing 1\% BSA for $45 \mathrm{~min}$ at room temperature. Subsequently, the cells were incubated with DAPI (Vector Laboratories, Inc.) and sealed using anti-fading buffer (Bioworld Technology, Inc.).

Immunohistochemistry, and hematoxylin and eosin $(H \& E)$ staining. Under anesthesia, 0.1 M PBS (pH 7.4) containing ice-cold 4\% PFA was injected into the left cardiac ventricle of the rats for fixation before the eyeballs of the rats were removed and embedded in $4 \%$ PFA at $4^{\circ} \mathrm{C}$ for 1 day. After fixation, the eyeballs were dehydrated, embedded in paraffin and cut into $5-\mu \mathrm{m}$ sections. The central part of the eyeballs, through the optic nerve, were selected for immunohistochemical analysis. Each section was heated with $10 \mathrm{mM}$ sodium citrate buffer $(\mathrm{pH} 6.0)$ at the secondary boiling point $\left(100^{\circ} \mathrm{C}\right)$ for $10 \mathrm{~min}$ and then cooled for $30 \mathrm{~min}$ for antigen retrieval. Blocking, primary and secondary antibody labelling, and all washing steps were performed as mentioned above. Staining was observed using a confocal microscopy at a magnification of x 20 (Axio-Imager_LSM-800, ZEISS, Germany). H\&E staining was observed using an inverted fluorescence microscope at a magnification of $x 20$ (Nikon Corporation). The thicknesses of the inner retina $[\mathrm{RGC}+$ inner plexiform layer $(\mathrm{IPL})+$ inner
Table I._Sequences of the primers used in the present study.

Gene Primer sequence, 5'-3'

\section{Opa1}

Forward

Reverse

CAGCTGGCAGAAGATCTCAAG

Yme1

Forward CATGAGCAGGATTTTGACACC

Reverse

AGGATGCAATGCCAATCAAT

Oma1

Forward TGCCACTCTTCCTCCCATAC

Reverse

ACCAGTGCAAAAGCTCCTTG

Sirt1

Forward TGTTCCTCTTCACGCTGTCT

Reverse GGCACCGATCCTCGAACAAT

$\beta$-actin

Forward CGCTTTGGTGGTTCTGAAAGG

Reverse

CCCGCGAGTACAACCTTCTT CGACGAGCGCAGCGATA

$\beta$-actin nuclear

encoded variant

Forward

Reverse

CTGCTCTTTCCCAGATGAGG

COII

Forward CCACAGCACTGTAGGGGTTT

Reverse

TGAGCCATCCCTTCACTAGG TGAGCCGCAAATTTCAGAG

Opa1, optic atrophy 1; Oma1, overlapping activities with m-AAA protease 1; Yme1, yeast mitochondrial DNA escape 1; Sirt1, sirtuin1; COII, cytochrome c oxidase subunit II.

nuclear layer (INL)] were measured in the H\&E sections using the Image-pro Plus version 6.0 (Media Cybernetics) at every quarter point of each retinal cross-section, which were then averaged. Each group contained four eyeballs to be measured. A total of 10 images were obtained from each retinal section of every eyeball for measuring the average.

RGC labeling and quantification. Fluoro-Gold (Fluorochrome, LLC) was injected into the superior colliculi of the rats to retrogradely label the RGCs. The rats were anaesthetized with an intraperitoneal injection of $10 \%$ chloral hydrate and placed in a small stereotaxic instrument (RWD Life Science Co., Ltd.). The skull was then opened to identify the bregma spot and mark the injection site of the superior colliculus. A hole was then drilled at the designated point using a 25-gauge needle. In total, $1.5 \mu 15 \%$ Fluoro-Gold solution dissolved in $0.9 \%$ sodium chloride were injected into the superior colliculus of both hemispheres using a Hamilton syringe before the skin incision was sutured. The rats started to receive resveratrol treatment 7 days after Fluoro-Gold injection, specifically at 1 day before, at the time of and 1 day after I/R retina injury before being sacrificed 7 days after retinal I/R injury. The eyes were then enucleated and dissected at the corneal limbus, following which, the lenses were removed and the posterior segments were fixed in $4 \% \mathrm{PFA}$ at $4^{\circ} \mathrm{C}$ for $1 \mathrm{~h}$. The retina, with a 
distinctive 'four-leafed' shape, was then tiled onto glass slides. RGCs labeled with Fluoro-Gold in these four microscopic fields of the retina were viewed under a fluorescence microscope at $\mathrm{x} 20$ magnification (IX71, Olympus Corporation). The selected fields were located at $\sim 2 \mathrm{~mm}$ radially from the optic disc to account for the variations in retinal ganglion cell density. The number of RGCs were counted by two individuals in a double-blinded manner, where the averages of the two were taken as the final count.

Apoptosis assay. Apoptosis analysis in retinal cells was performed as described previously $(25,27)$. The preparation of sections $(5 \mu \mathrm{m})$ and the treatment of R28 cells were described above, following which a TUNEL assay was performed using In Situ Cell Death Detection kit, Fluorescein (Roche Applied Science) to detect apoptotic cells in accordance with manufacturer's protocol. Tissue sections were assessed using a confocal microscope at a magnification of x20 (Axio-Imager LSM-800, ZEISS, Germany). Digital images were obtained (SPOT; Diagnostic Instruments, Inc.) and Photoshop versions 5.5 and 7.0 (Adobe Systems, Inc.) was used to compile images.

Cell counting Kit-8 (CCK-8) assay. The viability of the cells was assessed using a CCK- 8 assay (BestBio Science). Cells in the logarithmic growth phase were seeded into 96-well culture plates at a density of $\sim 2.5-3 \times 10^{4}$ cells in $100 \mu 1$ culture medium. After the cells had adhered, they were serum starved or treated with resveratrol before being treated with $10 \mu \mathrm{l}$ CCK-8 Solution. An automatic microplate reader (Multiskan MK3; Thermo Fisher Scientific, Inc.) was used to measure the optical density value (OD) in each well at a wavelength of $450 \mathrm{~nm}$. Cell viability was calculated from the OD values in each well using the following formula: [(Treated cell OD-blank OD)/(control cell OD-blank OD)]x100\%.

SOD activity analysis. R28 cells were seeded into $60-\mathrm{mm}$ tissue culture dishes, serum starved and treated with or without resveratrol. Whole cell lysates were obtained by sonication at $20 \%$ amplitude, $20 \mathrm{kHz}, 130 \mathrm{~W}$ for $1 \mathrm{~min}$, five times each on ice, with saline and then centrifuged at $10,000 \mathrm{x} \mathrm{g}$ for $15 \mathrm{~min}$ at $4^{\circ} \mathrm{C}$. The supernatant was then assayed using an SOD kit (Nanjing Jiancheng Bioengineering Institute) according to the manufacturer's protocol. The OD value of each sample was measured using a Multiskan MK3 reader at a wavelength of $450 \mathrm{~nm}$. The SOD value was calculated according to the following formulas: SOD inhibition rate $(\%)=\left[\left(\mathrm{A}_{\text {Control group }}-\mathrm{A}_{\text {Control blank group }}\right)-\left(\mathrm{A}_{\text {Measurement group }}-\mathrm{A}_{\text {Measurement }}\right.\right.$ blank group $)] /\left(\mathrm{A}_{\text {Control group }}-\mathrm{A}_{\text {Control blank group }}\right) \times 100 \%$; and, SOD activity $(\mathrm{U} / \mathrm{mg})=$ SOD inhibition rate $(\%) / 50 \% x$ [reaction system $(0.24 \mathrm{ml}) /$ dilution factor $(0.02 \mathrm{ml})] / \mathrm{sample}$ protein concentration (mgprot $/ \mathrm{ml})$.

Mitochondrial (mt)DNA copy number (mitCN). Ezup column animal genomic DNA extraction kit (Sangon Biotech Co., Ltd.) was used to collect retinal DNA. Relative mitCNs in the retinal samples were then measured by RT-qPCR and corrected using nuclear DNA. The amplification of mitochondrial cytochrome c oxidase subunit II (COII) and $\beta$-actin (nuclear-encoded gene) were examined. The specific sequences of the primers used are shown in Table I.
Statistical analysis. Statistical analysis was performed using Microsoft Excel (Office 365; Microsoft Corporation) and statistical analysis was performed using GraphPad Prism version 6 (GraphPad Software, Inc.). Results are presented as the mean \pm standard deviation. Comparisons were performed using an ANOVA followed by a post-hoc Tukey's test. $\mathrm{P}<0.05$ was considered to indicate a statistically significant difference.

\section{Results}

Resveratrol protects the retina and RGCs from I/R injury in rats. In the present study, general histopathological changes in the retina 7 days after injury induction were first investigated using $\mathrm{H} \& \mathrm{E}$ staining to evaluate the effects of resveratrol on the retina following retinal I/R injury. Significant thinning of the retina was observed after I/R injury, particularly in the GCL, IPL and INL. Administration of resveratrol prevented this reduction in retinal thickness (Fig. 1A). The quantity of RGCs was assessed using retrograde Fluoro-Gold labeling. RGCs were labeled with Fluoro-Gold 1 week before I/R, and the number of RGCs were counted 7 days after I/R or I/R + resveratrol. A significant reduction in the number of RGCs was observed 7 days after I/R, which was significantly reversed by the administration of resveratrol (Fig. 1B). Statistical analysis of inner retinal thickness (Fig. 1C) and RGC counts (Fig. 1D) were performed.

To investigate the effects of resveratrol on the retina further, TUNEL staining was performed 1, 3 and 7 days after I/R injury to explore the effects of resveratrol on apoptosis. Compared with the control group (day 0), there was an increase in the number of TUNEL-positive cells observed in the GCL and INL of the I/R group on day 1 (Fig. 2). A strong TUNEL-positive fluorescent signal was observed in the ONL of the I/R group on day 3, whilst almost no fluorescence was observed in the retina 7 days after I/R. Resveratrol treatment reduced the levels of cell apoptosis on days 1,3 and 7 after I/R.

Resveratrol regulates Opal protein and $m R N A$ expression following retinal $I / R$ injury. Resveratrol has been previously demonstrated to be a critical activator of Sirt1 (28). To verify the effect of resveratrol on Sirtl regulation, the expression profile of Sirt1 was examined. Four time points following I/R ( $0,1,3$ and 7 days) assessed, and the expression of the Sirt1 protein was found to be significantly lower only 7 days after I/R (Fig. 3A). Subsequently, to assess the effect of resveratrol on Sirt 1 expression in the I/R model, rats were sacrificed 7 days after I/R injury with or without resveratrol treatment. Intraperitoneal injections of resveratrol partially restored the expression of the Sirt1 protein and mRNA expression (Fig. 3B and C). Immunofluorescence staining showed that Sirt1 was primarily expressed in GCL, INL and ONL of the normal retina, and was found to be reduced 7 days after I/R injury. Resveratrol treatment partially restored Sirt1 expression following I/R (Fig. 3D).

The effect of resveratrol on Opal expression was a primary focus of the present study. It was found that at the selected time points after I/R injury, Opa1 protein expression also exhibited a decreasing trend, which was statistically significant only 7 days after I/R (Fig. 4A). Therefore, to investigate the effect of resveratrol on Opal expression 
A

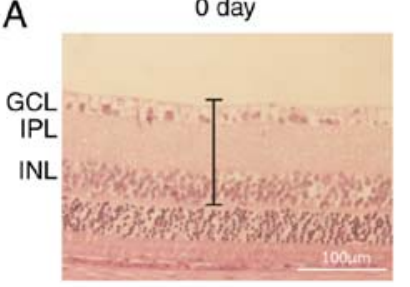

C

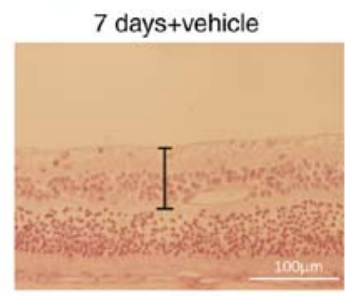

F

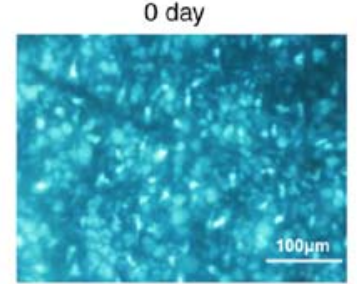

$\mathrm{H}$

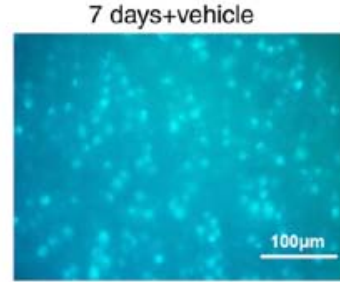

B
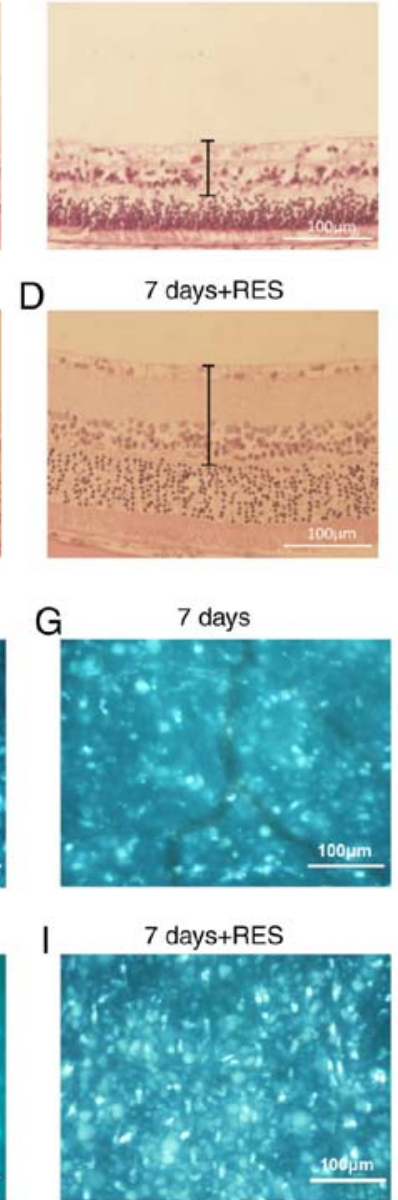
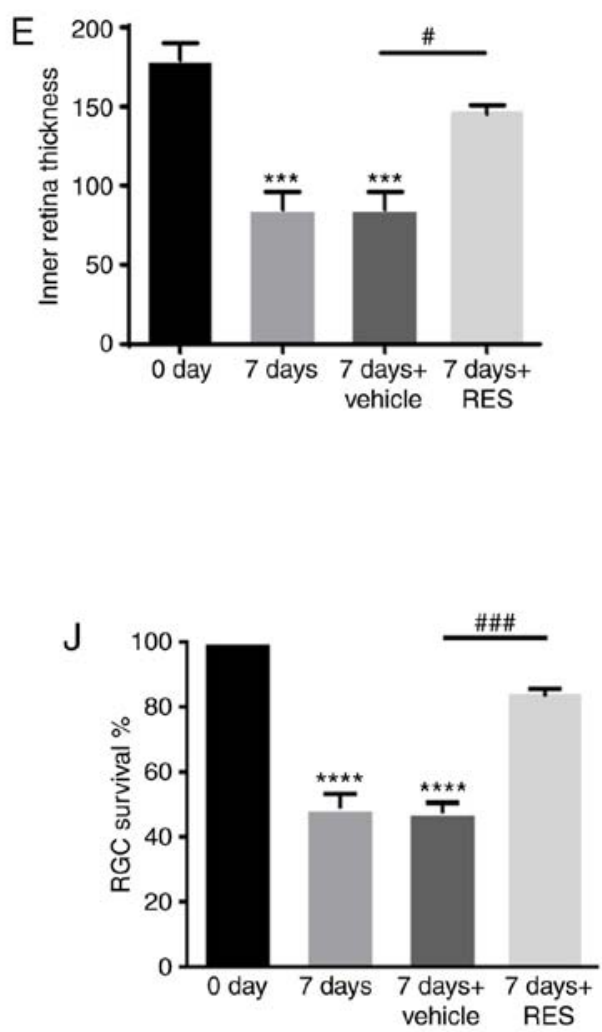

Figure 1. H\&E staining and Fluoro-Gold retrograde marker. (A-D) H\&E staining was observed using an inverted fluorescence microscope. Magnification x20. (E) Quantitative analysis of inner retina (GCL+IPL+INL) thickness variation. (F-I) Tiled retinas were examined 7 days after I/R and I/R + RES and were observed using an inverted fluorescence microscope. Magnification x40. (J) Quantitative analysis of Fluoro-Gold staining of RGCs. $\mathrm{n}=3$ per group. Scale bar, $100 \mu \mathrm{m} .{ }^{* * *} \mathrm{P}<0.001,{ }^{* * * *} \mathrm{P}<0.0001$ vs. 0 day; ${ }^{\#} \mathrm{P}<0.05,{ }^{\# \# \#} \mathrm{P}<0.001$ vs. 7 days + vehicle group. RES, resveratrol; GCL, ganglion cell layer; IPL, inner plexiform layer; INL, inner nuclear layer; H\&E, hematoxylin and eosin; I/R, ischemia/reperfusion; RGC, retinal ganglion cell.

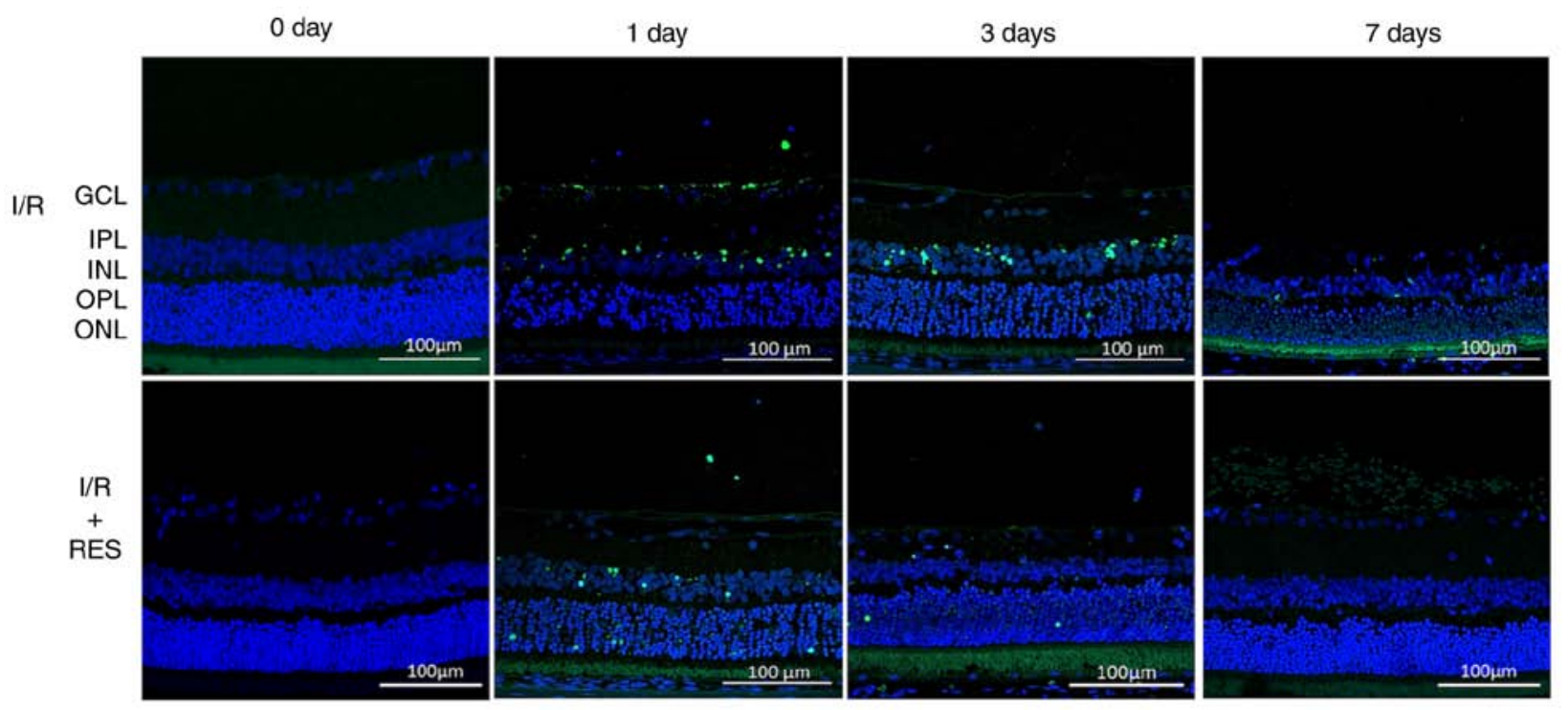

Figure 2. TUNEL staining to detect apoptosis. Retinal paraffin section TUNEL staining observed using a confocal microscope. In the normal retinal paraffin section, no fluorescence was observed following TUNEL staining. TUNEL staining of I/R $1 \mathrm{~d}$ retinal paraffin sections exhibited strong fluorescence in GCL and INL. In the TUNEL staining of I/R $3 \mathrm{~d}$ retinal paraffin sections, ONL exhibited a stronger fluorescence signal. TUNEL staining of I/R 7 days retinal paraffin sections showed no obvious fluorescence signal. I/R 0 and 7 days retinal paraffin sections showed no significant fluorescence changes following RES treatment. RES significantly attenuated the fluorescence signal induced by apoptosis in GCL at I/R 1 and 3 days. Scale bar, $100 \mu$ m. Blue, DAPI; green, TUNEL-positive cells. RES, resveratrol; INL, inner nuclear layer; IPL, inner plexiform layer; GCL, ganglion cell layer; I/R, ischemia/reperfusion. 

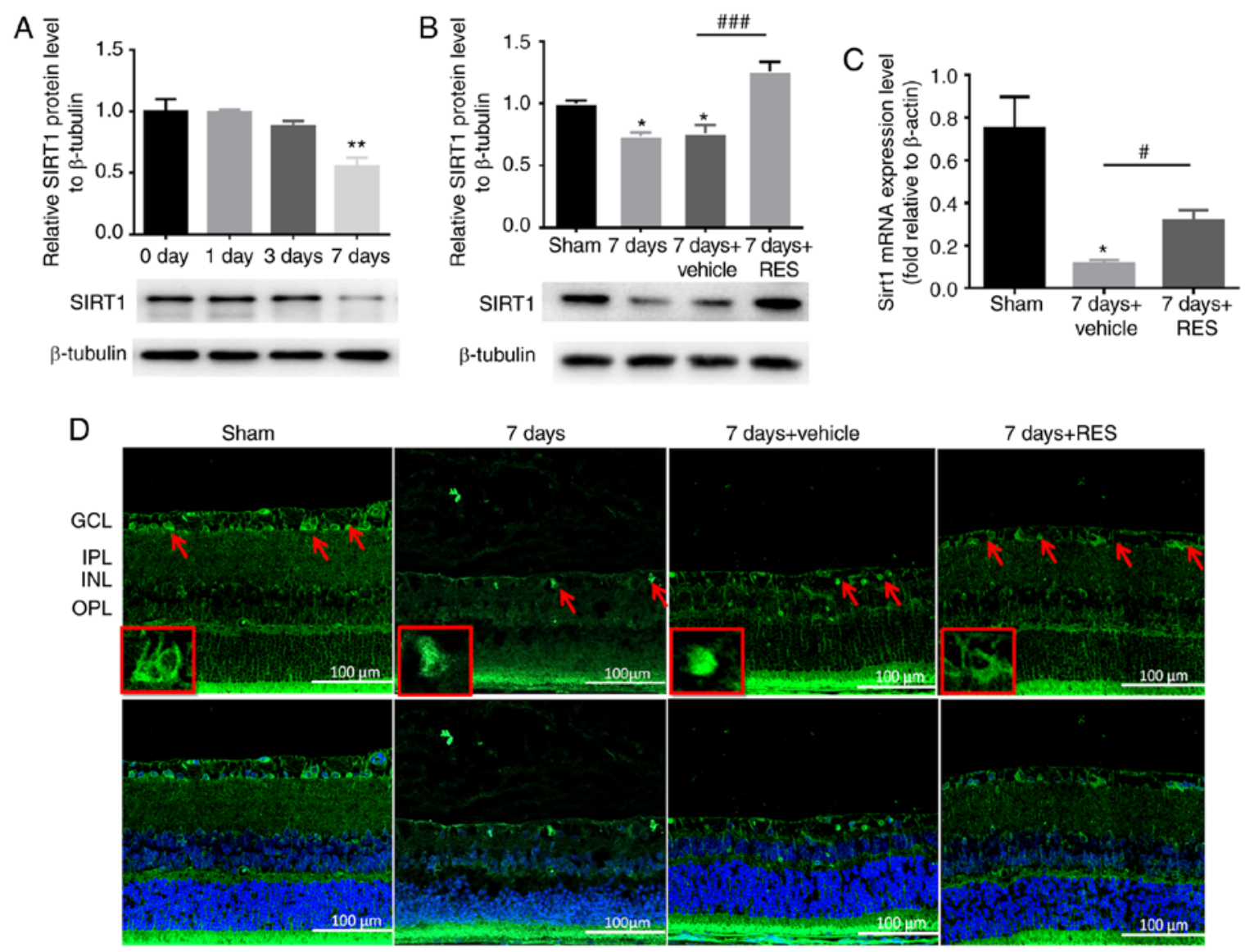

Figure 3. RES affects Sirt1 protein and gene expression following I/R injury. (A) Sirt1 protein expression gradually decreased over time, and this decrease was statistically significant at $I / R 7$ days. $n=3$ rats per group. ${ }^{* *} \mathrm{P}<0.01$ vs. 0 day group. (B and $C$ ) Intraperitoneal injection of RES restored Sirt1 protein and gene expression to some extent. $\mathrm{n}=3$ rats per group. ${ }^{*} \mathrm{P}<0.05$ vs. sham group; ${ }^{~} \mathrm{P}<0.05,{ }^{\# \# \#} \mathrm{P}<0.001$ vs. 7 days + vehicle group. (D) Confocal microscopy was used to observe the localization of Sirt1 in the retina. Magnification, x20. Sirt1 is primarily expressed in GCL, INL and ONL of normal retina. The expression of Sirt1 in the retina was significantly reduced 7 days after I/R injury. Resveratrol partly restores Sirt1 expression. Red arrow indicates the expression of Sirt1 in GCL. Scale bar, $100 \mu \mathrm{m}$. RES, resveratrol; GCL, ganglion cell layer; IPL, inner plexiform layer; INL, inner nuclear layer; I/R, ischemia/reperfusion; Sirt1, sirtuin1.

in the $\mathrm{I} / \mathrm{R}$ model, the rats were sacrificed 7 days after $\mathrm{I} / \mathrm{R}$ injury with or without resveratrol treatment. Intraperitoneal injection of resveratrol was shown to partially restore Opal protein and gene expression (Fig. 4B and C). The localization of Opa1 expression were then elucidated by immunofluorescence staining in the adult rat retinal tissues. It was observed that positive Opal expression (green fluorescence) was primarily present in the GCL, IPL, INL and outer plexiform layer. On day 7 after I/R injury, the expression of Opal was found to be reduced in all layers of the retina, which was significantly reversed by resveratrol treatment in various layers of the retina (Fig. 4D).

In addition, to investigate the effects of resveratrol on mtDNA in the I/R model, mitCN was measured at the selected time points ( $0,1,3$ and 7 days). A significant reduction $(\sim 50 \%)$ was observed in the mitCN in the retina 7 days after I/R compared with that in the sham group (Fig. 5A). However, resveratrol treatment did not reverse this change (Fig. 5B).

Resveratrol regulates the ratio of L-Opal/S-Opal. In mammalian cells, strict regulation of the L-Opa1/S-Opa1 ratio is required for a physiologically functioning mitochondrial network. In the present study, it was found that resveratrol increased the L-Opa1/S-Opa1 ratio (Fig. 6A). To investigate the detailed underlying mechanism, RT-qPCR was performed to study the influence of resveratrol on Oma1 and Yme1, two post-transcriptases that have previously been reported to regulate Opal $(29,30)$. The expression of Omal was found to be increased 7 days after $I / R$, which was reversed by resveratrol (Fig. 6B). The expression profile of Yme1 expression was opposite to that of Omal, with significant reductions 7 days after $\mathrm{I} / \mathrm{R}$, and upregulation after resveratrol treatment (Fig. 6C).

Effects of resveratrol on apoptosis, activity and the vitality of $S O D$ in $R 28$ cells. The effects of resveratrol on apoptosis was next explored using TUNEL staining 12, 24 and $48 \mathrm{~h}$ after serum deprivation. Compared with those in the control and solvent control group, a higher number of TUNEL-positive cells were observed in the serum deprivation group $(12,24$ and $48 \mathrm{~h}$ ), suggesting that serum deprivation can cause R28 cell apoptosis. Consistent with observations in vivo, resveratrol treatment also reversed this change (Fig. 7). The viability of R28 cells was then determined using a CCK-8 assay (Fig. 8A-C). Compared with that in the control group, the viability of R28 cells was found to be significantly reduced in the solvent control group (DMSO for 12, 24 and $48 \mathrm{~h}$ ). Cell viability in cells $12 \mathrm{~h}$ after serum deprivation was similar to that in the solvent control group. However, cells exhibited 

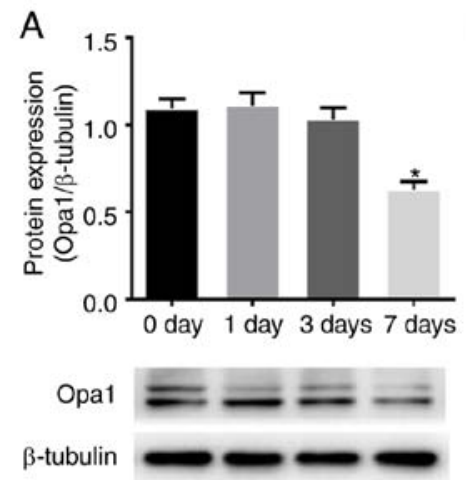
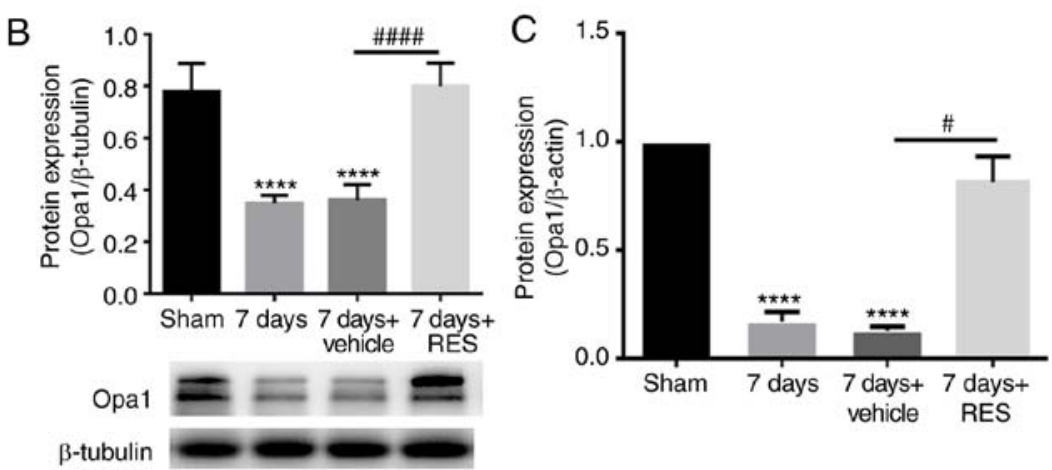
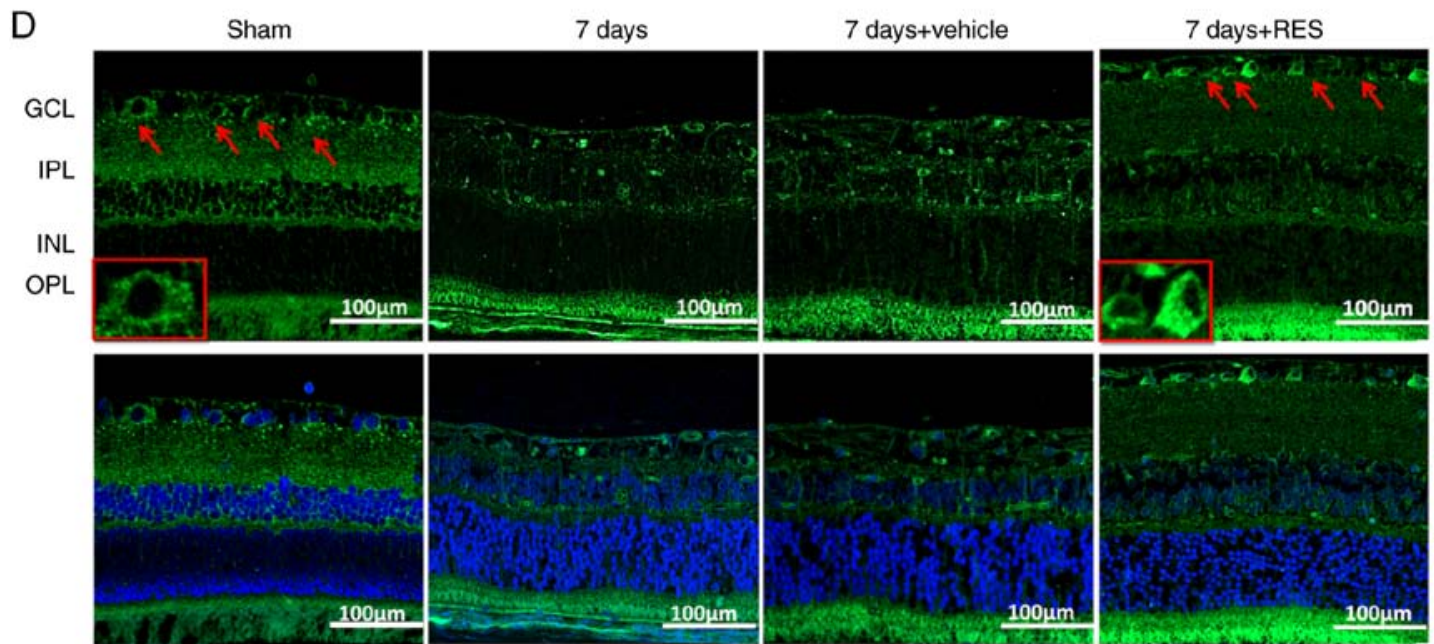

Figure 4. RES influences the expression and localization of OPA1 following I/R injury. (A) Protein expression levels of OPA1 gradually decreased, and this decrease was statistically significant at $\mathrm{I} / \mathrm{R} 7$ days. $\mathrm{n}=3$ rats per group. ${ }^{*} \mathrm{P}<0.05$ vs. 0 day group. (B and $\mathrm{C}$ ) Intraperitoneal injection of RES restored $\mathrm{OPA} 1$ protein and gene expression to some extent. $\mathrm{n}=3$ rats per group. ${ }^{* * * *} \mathrm{P}<0.0001$ vs. sham group; ${ }^{*} \mathrm{P}<0.05,{ }^{\# \# \#} \mathrm{P}<0.0001$ vs. 7 days + vehicle group. Confocal microscopy was used to observe the localization of OPA1 in the retina. Magnification, x20. (D) OPA1 is primarily expressed in GCL, IPL, INL and OPL of the normal retina. Expression of OPA1 was not observed in any layer of the retina 7 days after I/R injury. Resveratrol restored OPA1 expression. Red arrow indicates the expression of OPA1 in GCL. Scale bar, $100 \mu \mathrm{m}$. RES, resveratrol. GCL, ganglion cell layer; IPL, inner plexiform layer; INL, inner nuclear layer. I/R, ischemia/reperfusion; OPA1, optic atrophy 1.

A

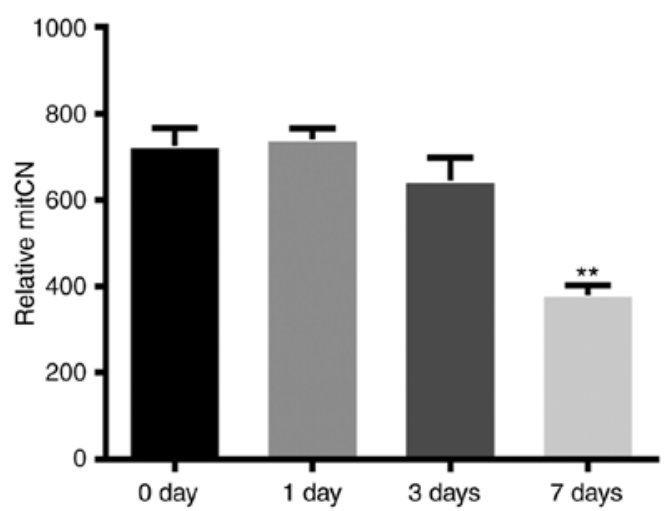

B

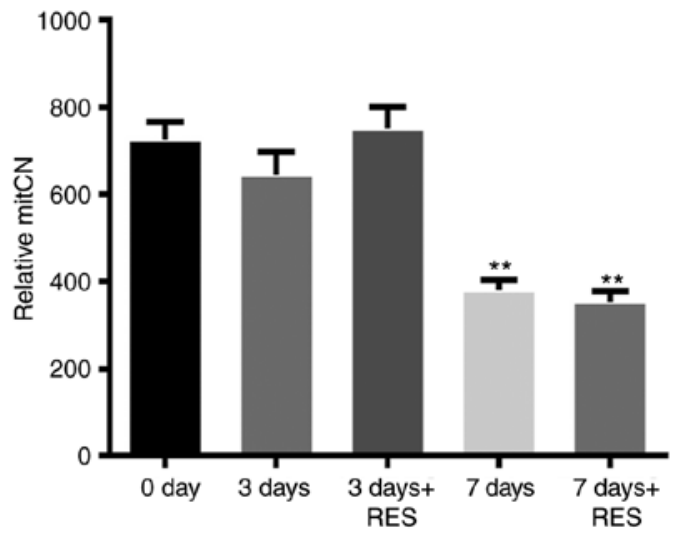

Figure 5. Change in mitCN in the retina following I/R injury. (A) mitCN in the retina gradually decreased, and this decrease was statistically significant in $\mathrm{I} / \mathrm{R}$ 7 days + vehicle. (B) Intraperitoneal injection of RES did not reverse the reduction in mitCN. $n=4$ rats per group. ${ }^{* *} \mathrm{P}<0.01$ vs. 0 day group. RES, resveratrol; mtDNA, mitochondrial DNA; mitCN, mtDNA copy number; $\mathrm{I} / \mathrm{R}$, ischemia/reperfusion.

lower cell viability compared with that in the solvent control group 24 and $48 \mathrm{~h}$ after serum deprivation, suggesting that the effect of serum deprivation on cell viability is time-dependent. Resveratrol treatment was demonstrated to partially reverse this reduction in cell viability. To investigate the relationship between SOD activity and apoptosis, the activity of SOD in R28 cells was also examined. After $24 \mathrm{~h}$ of serum deprivation, the activity of SOD was found to be significantly reduced, and this was attenuated by resveratrol treatment (Fig. 8D). 

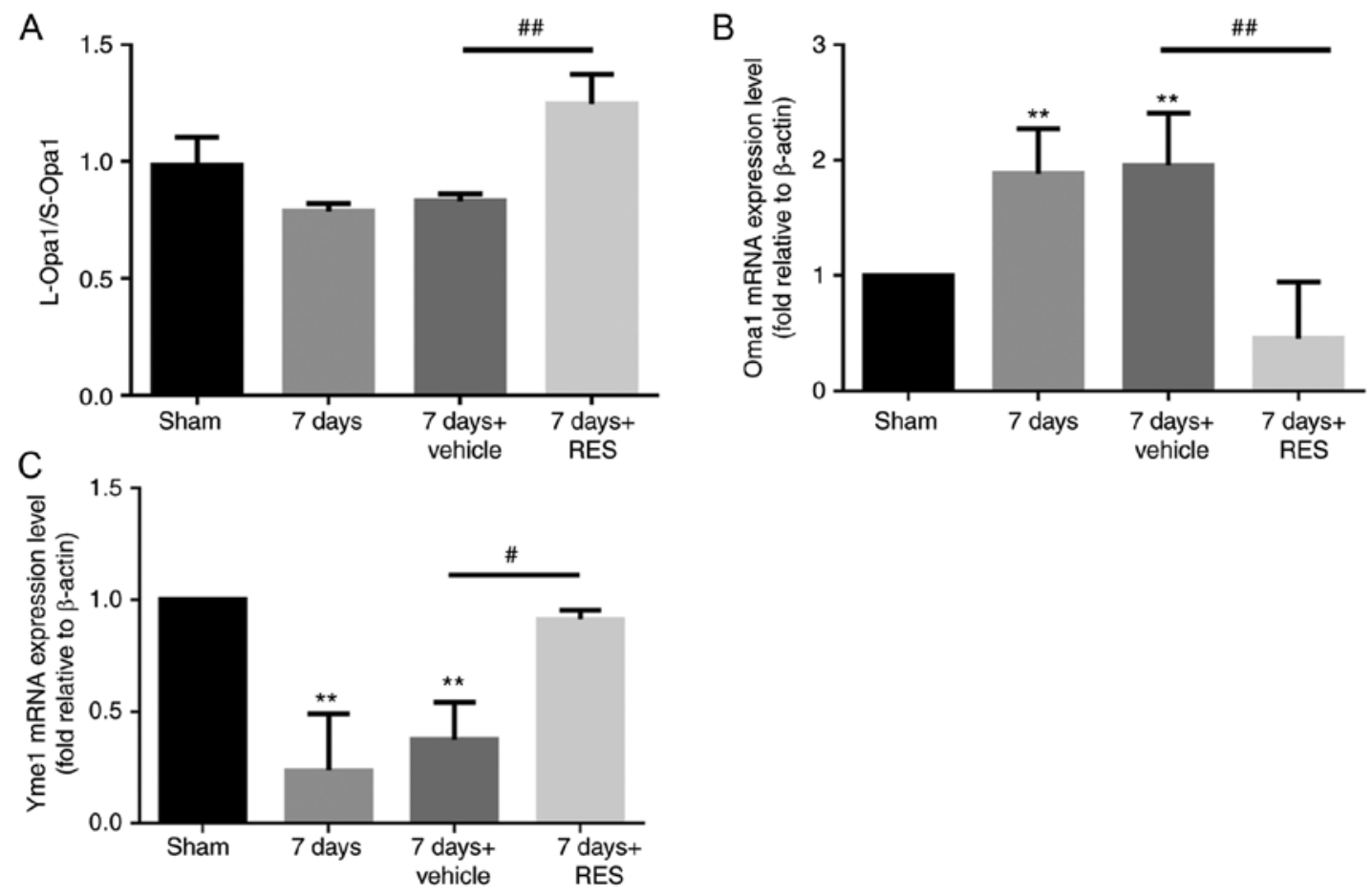

Figure 6. RES affects the gene expression levels of Oma1 and Yme1 genes and in-turn affects the L-Opa1/S-Opa1 ratio. (A) Opa1-L/Opa1-S ratio at the protein level. ${ }^{\# \#} \mathrm{P}<0.01$ vs. 7 days + vehicle group. (B and C) Omal and Yme1 mRNA expression levels in the retina of the sham group, 7 days I/R group, 7 days I/R + vehicle group and 7 days $\mathrm{I} / \mathrm{R}+\mathrm{RES}$ group. Graphs represent $\mathrm{Oma} 1$ and $\mathrm{Yme} 1$ gene expression levels. $\mathrm{n}=3$ rats per group. ${ }^{* *} \mathrm{P}<0.01 \mathrm{vs}$. sham group; ${ }^{\#} \mathrm{P}<0.05$, ${ }^{\# \#} \mathrm{P}<0.01$ vs. 7 days + vehicle group. I/R, ischemia/reperfusion; OPA1, optic atrophy 1, Oma1, overlapping activities with m-AAA protease 1; Yme1, yeast mitochondrial DNA escape 1.

Effects of resveratrol on Opal expression and localization in R28 cells. Compared with the control cells, Opa1 expression was shown to be significantly reduced 24 and $48 \mathrm{~h}$ after serum deprivation (Fig. 9A), which was partially attenuated by resveratrol treatment (Fig. 9B). Immunostaining of R28 cells was subsequently performed to determine the localization of Opa1. Opa1 was found to be expressed in the cytoplasm, but neither serum deprivation nor resveratrol treatment resulted in a significant alteration in Opa1 localization (Fig. 9C).

\section{Discussion}

Irreversible damage to neurons in the retina results in deterioration of vision and serves a central role in a number of optical diseases, including glaucoma, age-associated macular degeneration and diabetic retinopathy (31). However, minimal success has been achieved to halt or reverse the onset and development of these types of vision loss by clinical interventions (32). Therefore, to explore potential therapeutic targets for such diseases in the eye, particular research attention should be paid to the underlying molecular mechanism of retinal neuronal injury induction. In the present study, the potential effects of resveratrol on RGC following I/R injury and in vitro serum deprivation models were investigated, with a particular focus on the effects of resveratrol on the expression of Opal in vitro and in vivo. Resveratrol treatment was found to inhibit retinal damage, RGC loss and apoptosis following I/R injury and in in vitro serum deprivation models. In addition, resveratrol also altered the expression profiles of Omal and Ymel at the mRNA level, two primary proteins responsible for the post-transcriptional cleavage of Opa1, thereby increasing the L-Opa1/S-Opa1 ratio. The present study also showed that resveratrol partially reversed the reduction in Opal expression and the SOD activity caused by I/R. Thus, the results suggest that resveratrol treatment can protect RGCs by increasing Opa1 expression and regulating the expression of the post-transcriptional proteases of Opal in the ischemic retina.

The present study contributes information on the influence of resveratrol treatment on the ischemic retina. Resveratrol has attracted significant attention due to its previously reported neuroprotective, antitumorigenic and antioxidant properties (33). Zhang et al (34) previously reported that resveratrol can alleviate retinal damage and RGC-5 cell apoptosis by activating the 5'-AMP-activated protein kinase/peroxisome proliferator-activated receptor $\gamma$-coactivator 1 signaling pathway in addition to restoring RGC malfunction. Lindsey et al (35) also suggested that long term dietary resveratrol supplements can alter the expressional patterns of endoplasmic reticulum chaperones to protect against RGC dendrite loss. In the present study, a retinal I/R animal model was used, where increased IOP resulted in retinal circulatory disturbances and increased levels of reactive oxygen species and free radicals that attack cell structures and proteins during reperfusion, resulting in significant tissue damage $(36,37)$. Results from the present study suggested that resveratrol treatment significantly reduced retinal damage, RGC loss and apoptosis in I/R injury models, consistent with previous studies. Additionally, the same conclusions were drawn from the in vivo experiments. R28 cells have been previously used 

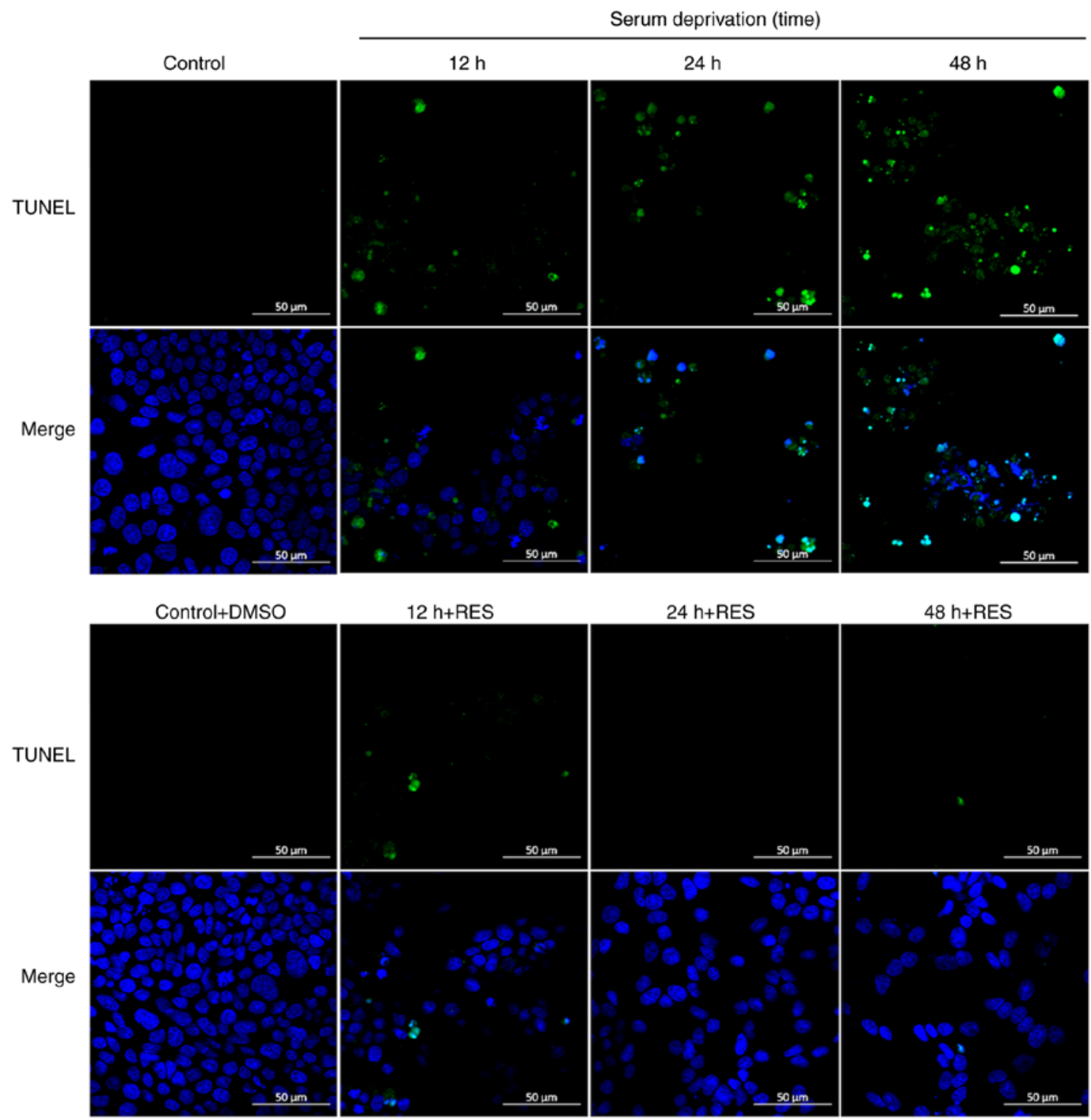

Figure 7. Resveratrol affects apoptosis of R28 cells. R28 cells treated with or without RES, were stained with TUNEL, 12,24 and 48 h after serum deprivation and visualized using confocal microscopy. No TUNEL-positive cells were observed in the control group or the control + RES group. The presence of TUNEL-positive cells gradually increased in the serum deprived cells over time. The increase in apoptotic cells in the serum deprived cells was attenuated by RES treatment. Blue, DAPI; green, TUNEL-positive cell. Scale bar, $50 \mu \mathrm{m}$. Magnification, x20. RES, resveratrol.

for in vitro and in vivo retinal cell behavior experiments (38) Serum deprivation was induced to measure the degree of apoptosis and explore potential protective interventions (39). Serum deprivation-induced damage has been reported to result from the lack of nutrients in the cell culture (39-42). In the present study, it was found that serum deprivation resulted in reduced R28 cell viability along with reduced apoptosis. Resveratrol treatment significantly improved the viability of R28 cells and partially prevented apoptosis. In particular, two notable observations were made based on the TUNEL staining in the retina. Although the levels of cell apoptosis in the GCL and INL layers were reduced, apoptotic cells could be observed in the ONL in I/R+RES group. Such multifaceted effects of resveratrol in the different retinal layers may be associated with the cellular distribution of the adenosine receptor subtypes. Adenosine A2 receptors are expressed predominantly in the GCL and INL (43), whilst adenosine A3 receptors are primarily found in the ONL (44). Activated A2 receptors can mediate the protective effects on ischemic neurons, whereas A3 receptors have been previously documented to serve a noxious role in triggering neuron apoptosis. Therefore, it is hypothesized that resveratrol is a non-selective adenosine receptor agonist that can induce apoptosis in the ONL whilst inhibiting this process in the INL and GCL, although the detailed mechanism requires further study (45-47). In addition, it is worth noting that TUNEL staining in the retina was negative 7 days after I/R. The possible cause of this may be that TUNEL stained the $3^{\prime}$ end of the cleaved DNA during apoptosis (48). Apoptosis is a gradual and phased process, such that following progression to a certain stage, apoptotic bodies are gradually engulfed by neighboring cells or phagocytic cells in vivo (49).

Mitochondrial dysfunction is considered to be the pivotal pathological change in the process of RGC loss during glaucoma development, which has consistently been the primary focus of research on its etiology (50). A number of proteins have been reported to participate in maintaining 
A
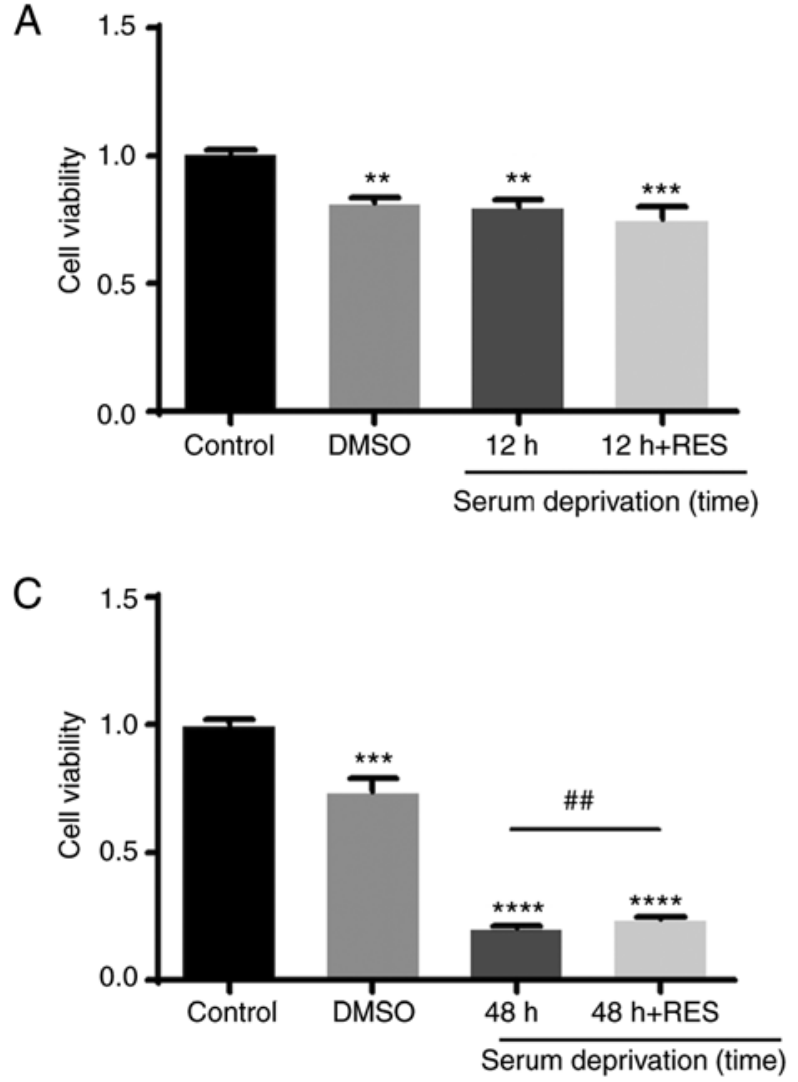
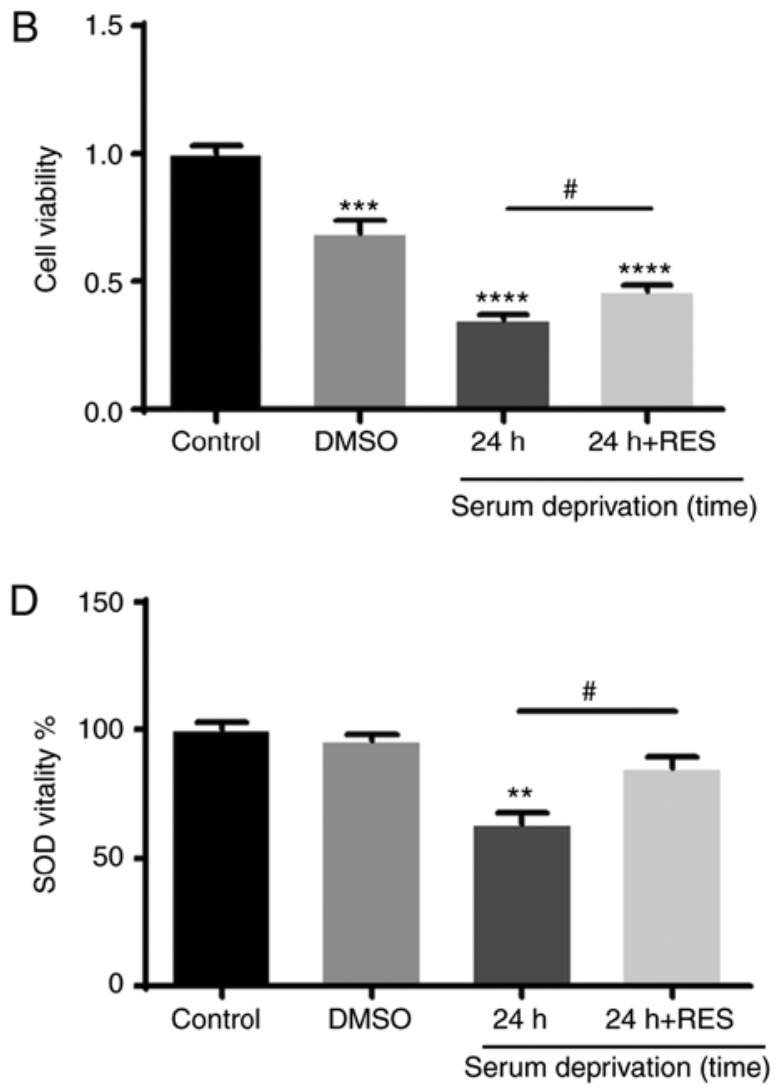

Figure 8. Resveratrol affects the activity of SOD in R28 cells. The viability of R28 cells was detected using a Cell Counting Kit-8 assay. (A) Compared with the control group, the viability of R28 cells was significantly reduced in the solvent control group (treated with DMSO for 12 h), a similar reduction was also observed in the cells that had been serum deprived cells for $12 \mathrm{~h}$. Compared with the cells that had been serum deprived cells for $12 \mathrm{~h}$, there was no significant increase in R28 cell viability when treated with RES and serum deprived for $12 \mathrm{~h} .{ }^{* *} \mathrm{P}<0.01,{ }^{* * * *} \mathrm{P}<0.001$ vs. control group. (B) Cell viability of R28 cells was reduced in the solvent control group (treated with DMSO for $24 \mathrm{~h}$ ), a more significant reduction was observed in the cells that had been serum deprived cells for $24 \mathrm{~h}$. Compared to the cells that had been serum deprived for $24 \mathrm{~h}$, RES treatment partially restored the viability of $\mathrm{R} 28$ cells. ${ }^{* * * *} \mathrm{P}<0.001$, ${ }^{* * * *} \mathrm{P}<0.0001 \mathrm{vs}$. control group; ${ }^{\#} \mathrm{P}<0.05$ vs. $24 \mathrm{~h}$ of serum deprivation. (C) Serum deprivation for $48 \mathrm{~h}$ resulted in similar results to that of $24 \mathrm{~h}$ serum deprivation. ${ }^{* * * *} \mathrm{P}<0.001$, ${ }^{* * * *} \mathrm{P}<0.0001$ vs. control group. ${ }^{\# \#} \mathrm{P}<0.01$ vs. 48 h. (D) SOD activity in R28 cells was detected using a SOD kit. SOD activity was significantly reduced after $24 \mathrm{~h}$ of serum deprivation, and the decrease in activity was attenuated by RES treatment. ${ }^{* *} \mathrm{P}<0.01$, vs. control group; ${ }^{*} \mathrm{P}<0.05$ vs. $24 \mathrm{~h}$ of serum deprivation. RES, resveratrol; SOD, superoxide dismutase.

mitochondrial function. Opa1 is well known for its role in the regulation of mitochondrial dynamics, where it inhibits mitochondrial cristae remodeling and cytochrome c release $(13,51)$. Cytochrome c released into the cytosol can recruit pro-apoptotic signals and trigger downstream apoptotic events by binding between the two tryptophan (W) and aspartate (D)-rich WD domains of the apoptotic protease activating factor (Apaf-1), thereby irreversibly activating the apoptotic cascade (52). Cristae morphogenesis, which is induced by the reduction of Opal expression, may increase the probability of cytochrome c release $(53,54)$. In previous studies, Opal has been reported to serve a neuroprotective role in the retina by modulating mitochondrial function (55). Additionally, Opa1 has also been found to be significantly downregulated in the retina of Wistar rats following I/R injury (13). Opal mutations have been proposed to result in RGC dendropathy, increasing the susceptibility of RGCs to apoptosis and vulnerability to oxidative stress (56). A substantial number of studies focusing on the molecular mechanism by which Opal protects against RGC loss have been performed. Hu et al (57) hypothesized that during experimental glaucoma, Opal exerted a protective effect on RGCs by promoting mitochondrial fusion and enhancing Parkin-mediated mitophagy (57). This previous study also suggested that the Opa-1-mediated downregulation of Bax, a pro-apoptotic member of the Bcl-2 family, coupled with the activation of Bcl-2, can alleviate ischemia-induced RGC loss (57). In the present study, at the selected I/R time points, the expression of the Opa1 protein also exhibited a decreasing trend in the retina of SD rats. Consistent with these findings, serum deprivation also resulted in the reduction of Opa1 expression in R28 cells. These observations support the notion that Opa1 may protect against RGC apoptosis. Resveratrol has been previously reported to induce mitochondrial biogenesis and improve mitochondrial function $(58,59)$. In addition, it has also been shown to significantly reverse rotenone-induced reductions in Opa1 protein and mRNA expression in PC12 cells (60). Similar results were obtained following resveratrol treatment in the I/R retinal injury and serum deprivation models used in the present study. These observations suggest that resveratrol may confer therapeutic potential for the treatment of RGC apoptosis by increasing Opa1 expression.

Results from the present study also provided evidence that resveratrol can upregulate the L-Opa1/S-Opa1 ratio by modulating the proteolytic processing of Opa1. In mammals, L-Opal is anchored onto the inner membrane, whereas 
A

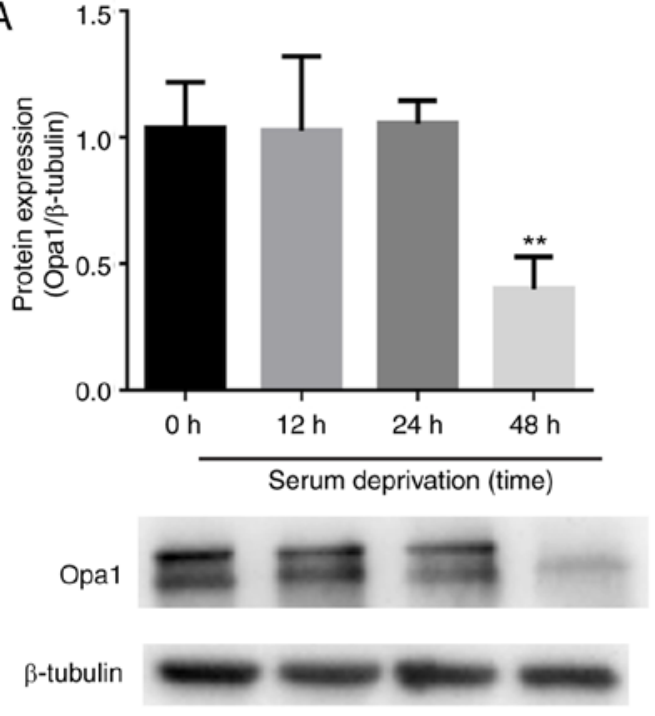

$\mathrm{B}$

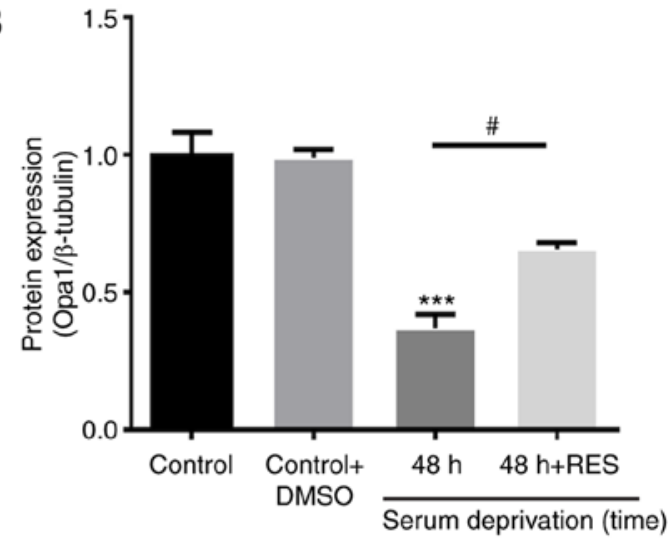

Opa1

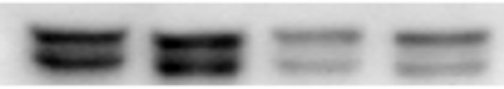

$\beta$-tubulin

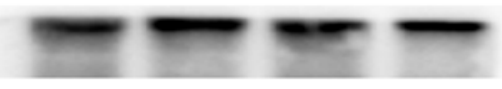

$48 \mathrm{~h}+\mathrm{RES}$

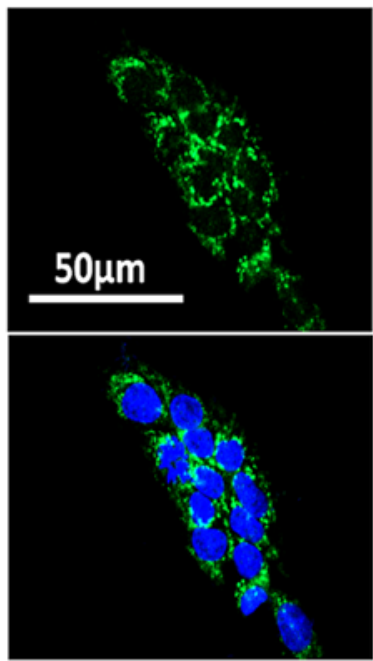

Figure 9. Effect of serum deprivation and RES on the localization and expression of OPA1 in R28 cells. Confocal microscopy was used to observe the localization and expression of OPA1 in R28 cells. Magnification, $\mathrm{x} 20$. (A) OPA1 expression was significantly reduced after $48 \mathrm{~h}$ of serum deprivation. ${ }^{* *} \mathrm{P}<0.01 \mathrm{vs} .0 \mathrm{~h}$. (B) Simultaneous RES treatment increased OPA1 expression compared with serum deprivation alone. ${ }^{* * *} \mathrm{P}<0.001$ vs. control group. ${ }^{*} \mathrm{P}<0.05$ vs. $48 \mathrm{~h}$ of serum deprivation. (C) Expression and localization of OPA1 in R28 cells under normal conditions, serum deprivation for $48 \mathrm{~h}$ with and without RES. $\mathrm{n}=6 \mathrm{per}$ group. Scale bar, $50 \mu \mathrm{m}$. RES, resveratrol; OPA1, optic atrophy 1.

S-Opa1 is soluble (61). S-Opa1 is generated by the cleavage of L-Opa1 in the transmembrane domain (61). Mitochondrial fusion is determined by the tightly regulated L-Opa1/S-Opa1 ratio, where L-Opa1 facilitated mitochondrial inner membrane fusion and S-Opal promoted mitochondrial fission. Excessive mitochondrial fission can induce mitochondrion fragmentation, resulting in mitochondrial dysfunction and cell death (62-66). Under physiological conditions, Oma1 is degraded by sufficient ATP and Yme-1 serves a pivotal role in promoting mitochondrial fusion whilst inhibiting apoptosis by generating L-Opa1. By contrast, during conditions of high oxidative stress, Omal can promote mitochondrial fragmentation by rapidly converting L-Opa1 into S-Opa1, which triggers the ubiquitination of proteins in the outer membrane to be removed by mitophagy (67-69). In the retina, 7 days after I/R injury, the mRNA expression levels of Ymel were found to be significantly reduced, whilst that of Omal was found to be increased, and this was reversed by resveratrol treatment. This observation suggested that resveratrol administration may increase the L-Opa1/S-Opa1 ratio by regulating the post-transcriptional cleavage of Opal in the ischemic retina. To the best of our knowledge, this was the first time that resveratrol was demonstrated to influence the L-Opa1/S-Opal ratio in ischemic retina. However, whether these changes in Opa1 post-transcriptional cleavage are direct effects of resveratrol administration warrant further investigation.

To assess whether resveratrol can effectively improve mitochondrial quality, the mitCN in the retina was measured using RT-qPCR. Accumulating evidence provided by previous genotyping studies demonstrated that depletion of mtDNA, which is one of the biomarkers of mitochondrial quality, can be detected in patients with glaucoma (70,71). In addition, it has been previously reported that Opal is pivotal in maintaining mitCNs and mitochondrial morphology (72). 
Supporting this, an increased number of mtDNA-deficient cells with mitochondrial fragmentation is observed in organisms encoding the mutated version of the Opa1 gene (73). The present study reported a $\sim 50 \%$ decrease in the mitCN within the retina 7 days after $\mathrm{I} / \mathrm{R}$, consistent with the results from previous studies. However, no notable changes were detected after resveratrol treatment, contrary to that of Chen et al (74), who demonstrated that resveratrol could maintain mitCNs in a serum deprivation model of RGCs. A possible explanation for this striking difference in mitCNs following resveratrol treatment in vivo and in vitro may be that, compared with the cell culture model, the animal model is considerably more complex as a number of uncontrollable factors which can influence cell behavior and gene expression, such as endogenous growth factors, should be taken into consideration. When investigating the protective mechanisms of resveratrol on the ischemic retina, monolayer culture models alone cannot be considered as a reliable tool compared with animal studies (75-77). Therefore, it is crucial that further research into this specific mechanism is performed in vivo.

In vitro data in the present study demonstrated that resveratrol supplementation can effectively reduce ROS production. Excessive production of reactive oxygen species can also be regarded as the main cause of turbulence in bioenergetic homeostasis and mitochondrial dysfunction. Oxidative stress can lead to the suppression of pro-survival signaling and pro-apoptotic signaling activation, in turn activating apoptosis downstream of caspase activation (78). SOD is one of the ROS scavengers that rapidly converts superoxide radicals into $\mathrm{H}_{2} \mathrm{O}_{2}$ to efficiently prevent deteriorations in mitochondrial function and apoptosis (79). It has been previously reported that resveratrol can induce superoxide dismutase in the liver to inhibit ethanol-induced oxidative stress (80). To initially investigate the relationship among SOD activity, apoptosis and the regulatory role of resveratrol in RGCs, SOD activity of R28 cells was first assessed. After $24 \mathrm{~h}$ of serum deprivation, the activity of SOD was found to be reduced, and this was attenuated by resveratrol treatment.

These present findings may confer important implications for the development of potential therapeutic strategies against glaucomatous RGC loss. However, the present study has several limitations. The underlying molecular pathway between resveratrol treatment and Opal post-transcriptional cleavage requires further elucidation. Additionally, in the present study, resveratrol was injected intraperitoneally into the rats. Since intraperitoneal injection of resveratrol is not a suitable method for delivery into humans, an optimized method of resveratrol administration should also be developed for its prospective clinical application (81).

In summary, the present study found that treatment with resveratrol exhibited protective effects on I/R-induced retinal injury and serum deprivation-induced R 28 cell apoptosis. In addition, resveratrol has also been found to exert protective effects on RGCs. Mechanistically, resveratrol was shown to regulate the expression of Opal and the activity of SOD. However, it remains necessary to further investigate the relationship between apoptosis, Opa1 and SOD activity to provide clearer evidence of the protective effects of resveratrol on RGCs, in particular in association with glaucoma.

\section{Acknowledgements}

We are grateful to Dr Lingfeng Li, Dr Hongdou Luo and Dr Weiwei Sheng (Affiliated Eye Hospital of Nanchang University, Jiangxi Research Institute of Ophthalmology and Visual Science ) for their guidance.

\section{Funding}

This study was supported by the National Natural Science Foundation of China (grant nos. 81271425, 81860170 and 81260148) and the Natural Science Foundation of Jiangxi (grant no. 20181ACG70010).

\section{Availability of data and materials}

The data sets used and/or analyzed during the present study are available from the corresponding author on reasonable request.

\section{Authors' contributions}

YP, MQ, PH and XZ conceived the study. YP, MQ, PH, KJ, RX, NS and XP performed the experiments. YP, MQ, PH and $\mathrm{XZ}$ analyzed the data. YP, MQ and XZ drafted the manuscript. All authors read and approved the final manuscript.

\section{Ethics approval and consent to participate}

All experiments were performed in accordance with the ARVO Statement for the Use of Animals in Ophthalmic and Vision Research and were approved and monitored by the Institutional Animal Care and Use Committee of Nanchang University (approval no. 2016NC-020-02).

\section{Patient consent for publication}

Not applicable.

\section{Competing interests}

The authors declare that they have no competing interests.

\section{References}

1. Bonomi L: Epidemiology of angle-closure glaucoma. Acta Ophthalmol Scand Suppl 236: 11-13, 2002.

2. Garcia-Valenzuela E, Shareef S, Walsh J and Sharma SC: Programmed cell death of retinal ganglion cells during experimental glaucoma. Exp Eye Res 61: 33-44, 1995.

3. Quigley HA, Nickells RW, Kerrigan LA, Pease ME, Thibault DJ and Zack DJ: Retinal ganglion cell death in experimental glaucoma and after axotomy occurs by apoptosis. Invest Ophthalmol Vis Sci 36: 774-786, 1995.

4. Almasieh M, Wilson AM, Morquette B, Cueva Vargas JL and Di Polo A: The molecular basis of retinal ganglion cell death in glaucoma. Prog Retin Eye Res 31: 152-181, 2012.

5. Williams PA, Harder JM, Foxworth NE, Cochran KE, Philip VM, Porciatti V, Smithies O and John SW: Vitamin $B_{3}$ modulates mitochondrial vulnerability and prevents glaucoma in aged mice. Science 355: 756-760, 2017.

6. Huang C, Zhang P, Wang W, Xu Y, Wang M, Chen X and Dong X: Long-term blue light exposure induces RGC-5 cell death in vitro: Involvement of mitochondria-dependent apoptosis, oxidative stress, and MAPK signaling pathways. Apoptosis 19: 922-932, 2014. 
7. Das A, Bell CM, Berlinicke CA, Marsh-Armstrong N and Zack DJ: Programmed switch in the mitochondrial degradation pathways during human retinal ganglion cell differentiation from stem cells is critical for RGC survival. Redox Biol 34: 101465, 2020.

8. Giacomello M, Pyakurel A, Glytsou C and Scorrano L: The cell biology of mitochondrial membrane dynamics. Nat Rev Mol Cell Biol 21: 204-224, 2020.

9. Lee S, Van Bergen NJ, Kong GY, Chrysostomou V, Waugh HS, O'Neill EC, Crowston JG and Trounce IA: Mitochondrial dysfunction in glaucoma and emerging bioenergetic therapies. Exp Eye Res 93: 204-212, 2011.

10. Schober MS, Chidlow G, Wood JP and Casson RJ: Bioenergetic-based neuroprotection and glaucoma. Clin Exp Ophthalmol 36: 377-385, 2008.

11. Dhingra A, Jayas R, Afshar P, Guberman M, Maddaford G, Gerstein J, Lieberman B, Nepon H, Margulets V, Dhingra R and Kirshenbaum LA: Ellagic acid antagonizes Bnip3-mediated mitochondrial injury and necrotic cell death of cardiac myocytes. Free Radic Biol Med 112: 411-422, 2017.

12. Geng J, Wei M, Yuan X, Liu Z, Wang X, Zhang D, Luo L, Wu J, Guo $W$ and Qin $Z H$ : TIGAR regulates mitochondrial functions through SIRT1-PGC1 $\alpha$ pathway and translocation of TIGAR into mitochondria in skeletal muscle. FASEB J 33: 6082-6098, 2019.

13. Sun Y, Xue W, Song Z, Huang K and Zheng L: Restoration of Opa1-long isoform inhibits retinal injury-induced neurodegeneration. J Mol Med (Berl) 94: 335-346, 2016.

14. Youle RJ and van der Bliek AM: Mitochondrial fission, fusion, and stress. Science 337: 1062-1065, 2012.

15. Frezza C, Cipolat S, Martins de Brito O, Micaroni M, Beznoussenko GV, Rudka T, Bartoli D, Polishuck RS, Danial NN, De Strooper B and Scorrano L: OPA1 controls apoptotic cristae remodeling independently from mitochondrial fusion. Cell 126 177-189, 2006

16. Baur JA and Sinclair DA: Therapeutic potential of resveratrol: The in vivo evidence. Nat Rev Drug Discov 5: 493-506, 2006.

17. Chong ZZ, Shang YC, Wang S and Maiese K: SIRT1: new avenues of discovery for disorders of oxidative stress. Expert Opin Ther Targets 16: 167-178, 2012.

18. Ahmed T, Javed S, Javed S, Tariq A, Šamec D, Tejada S, Nabavi SF Braidy N and Nabavi SM: Resveratrol and Alzheimer's disease: Mechanistic insights. Mol Neurobiol 54: 2622-2635, 2017.

19. Pandey AK, Bhattacharya P, Shukla SC, Paul S and Patnaik R: Resveratrol inhibits matrix metalloproteinases to attenuate neuronal damage in cerebral ischemia: A molecular docking study exploring possible neuroprotection. Neural Regen Res 10 $568-575,2015$

20. Richard T, Pawlus AD, Iglésias ML, Pedrot E, Waffo-Teguo P, Mérillon JM and Monti JP: Neuroprotective properties of resveratrol and derivatives. Ann N Y Acad Sci 1215: 103-108, 2011.

21. Abu-Amero KK, Kondkar AA and Chalam KV: Resveratrol and ophthalmic diseases. Nutrients 8: 200, 2016.

22. Zuo L, Khan RS, Lee V, Dine K, Wu W and Shindler KS: SIRT1 promotes RGC survival and delays loss of function following optic nerve crush. Invest Ophthalmol Vis Sci 54: 5097-5102, 2013.

23. Krishnamoorthy RR, Agarwal P, Prasanna G, Vopat K Lambert W, Sheedlo HJ, Pang IH, Shade D, Wordinger RJ, Yorio T, et al: Characterization of a transformed rat retina ganglion cell line. Brain Res Mol Brain Res 86: 1-12, 2001.

24. Liu B, Chen H, Johns TG and Neufeld AH: Epidermal growth factor receptor activation: An upstream signal for transition of quiescent astrocytes into reactive astrocytes after neural injury. J Neurosci 26: 7532-7540, 2006

25. Bennet D and Kim S: Effects of agmatine and resveratrol on RGC-5 cell behavior under light stimulation. Environ Toxicol Pharmacol 38: 84-97, 2014

26. Livak KJ and Schmittgen TD: Analysis of relative gene expression data using real-time quantitative PCR and the 2(-Delta Delta C(T)) method. Methods 25: 402-408, 2001.

27. Chintala SK, Zhang X, Austin JS and Fini ME: Deficiency in matrix metalloproteinase gelatinase B (MMP-9) protects against retinal ganglion cell death after optic nerve ligation. J Biol Chem 277: 47461-47468, 2002

28. Lagouge M, Argmann C, Gerhart-Hines Z, Meziane H, Lerin C, Daussin F, Messadeq N, Milne J, Lambert P, Elliott P, et al Resveratrol improves mitochondrial function and protects against metabolic disease by activating SIRT1 and PGC-1alpha. Cell 127: 1109-1122, 2006
29. Anderson CJ, Kahl A, Fruitman H, Qian L, Zhou P, Manfredi G and Iadecola C: Prohibitin levels regulate OMA1 activity and turnover in neurons. Cell Death Differ 27: 1896-1906, 2020.

30. Griparic L, Kanazawa T and van der Bliek AM: Regulation of the mitochondrial dynamin-like protein Opal by proteolytic cleavage. J Cell Biol 178: 757-764, 2007.

31. Osborne NN, Casson RJ, Wood JP, Chidlow G, Graham M and Melena J: Retinal ischemia: Mechanisms of damage and potential therapeutic strategies. Prog Retin Eye Res 23: 91-147, 2004.

32. Gao H, Zhang HL, Shou J, Chen L, Shen Y, Tang Q, Huang J and Zhu J: Towards retinal ganglion cell regeneration. Regen Med 7: 865-875, 2012.

33. Semba RD, Ferrucci L, Bartali B, Urpí-Sarda M, Zamora-Ros R, Sun K, Cherubini A, Bandinelli S and Andres-Lacueva C: Resveratrol levels and all-cause mortality in older community-dwelling adults. JAMA Intern Med 174: 1077-1084, 2014.

34. Zhang X, Feng Y, Wang Y, Wang J, Xiang D, Niu W and Yuan F: Resveratrol ameliorates disorders of mitochondrial biogenesis and dynamics in a rat chronic ocular hypertension model. Life Sci 207: 234-245, 2018

35. Lindsey JD, Duong-Polk KX, Hammond D, Leung CK and Weinreb RN: Protection of injured retinal ganglion cell dendrites and unfolded protein response resolution after long-term dietary resveratrol. Neurobiol Aging 36: 1969-1981, 2015.

36. Szabo ME, Droy-Lefaix MT, Doly $M$ and Braquet P: Free radical-mediated effects in reperfusion injury: A histologic study with superoxide dismutase and EGB 761 in rat retina. Ophthalmic Res 23: 225-234, 1991

37. Belforte N,Sande PH, de Zavalia N, Fernandez DC, Silberman DM, Chianelli MS and Rosenstein RE: Ischemic tolerance protects the rat retina from glaucomatous damage. PLoS One 6: e23763, 2011.

38. Seigel GM: Review: R28 retinal precursor cells: The first 20 years. Mol Vis 20: 301-306, 2014

39. Charles I, Khalyfa A, Kumar DM, Krishnamoorthy RR, Roque RS, Cooper N and Agarwal N: Serum deprivation induces apoptotic cell death of transformed rat retinal ganglion cells via mitochondrial signaling pathways. Invest Ophthalmol Vis Sci 46: 1330-1338, 2005.

40. Lee SB, Kim JJ, Kim TW, Kim BS, Lee MS and Yoo YD: Serum deprivation-induced reactive oxygen species production is mediated by Romo1. Apoptosis 15: 204-218, 2010.

41. Liu Q, Ju WK, Crowston JG, Xie F, Perry G, Smith MA, Lindsey JD and Weinreb RN: Oxidative stress is an early event in hydrostatic pressure induced retinal ganglion cell damage. Invest Ophthalmol Vis Sci 48: 4580-4589, 2007.

42. Kang KD, Andrade da Costa BL and Osborne NN: Stimulation of prostaglandin EP2 receptors on RGC-5 cells in culture blunts the negative effect of serum withdrawal. Neurochem Res 35: $820-829,2010$

43. Kvanta A, Seregard S, Sejersen S, Kull B and Fredholm BB: Localization of adenosine receptor messenger RNAs in the rat eye. Exp Eye Res 65: 595-602, 1997.

44. Grillo SL, McDevitt DS, Voas MG, Khan AS, Grillo MA and Stella SJ Jr: Adenosine receptor expression in the adult zebrafish retina. Purinergic Signal 15: 327-342, 2019.

45. Castillo A, Tolón MR, Fernández-Ruiz J, Romero J and Martinez-Orgado J: The neuroprotective effect of cannabidiol in an in vitro model of newborn hypoxic-ischemic brain damage in mice is mediated by $\mathrm{CB}(2)$ and adenosine receptors. Neurobiol Dis 37: 434-440, 2010

46. Dai SS, Zhou YG, Li W, An JH, Li P, Yang N, Chen XY, Xiong RP, Liu P, Zhao Y, et al: Local glutamate level dictates adenosine $\mathrm{A} 2 \mathrm{~A}$ receptor regulation of neuroinflammation and traumatic brain injury. J Neurosci 30: 5802-5810, 2010.

47. Von Lubitz DK, Lin RC, Popik P, Carter MF and Jacobson KA Adenosine A3 receptor stimulation and cerebral ischemia. Eur J Pharmacol 263: 59-67, 1994.

48. Kressel M and Groscurth P: Distinction of apoptotic and necrotic cell death by in situ labelling of fragmented DNA. Cell Tissue Res 278: 549-556, 1994.

49. Elmore S: Apoptosis: A review of programmed cell death. Toxicol Pathol 35: 495-516, 2007.

50. Hass DT and Barnstable CJ: Mitochondrial uncoupling protein 2 knock-out promotes mitophagy to decrease retinal ganglion cell death in a mouse model of glaucoma. J Neurosci 39: 3582-3596, 2019.

51. Olichon A, Guillou E, Delettre C,Landes T, Arnauné-Pelloquin L, Emorine LJ, Mils V, Daloyau M,Hamel C, Amati-Bonneau P, et al: Mitochondrial dynamics and disease, OPA1. Biochim Biophys Acta 1763: 500-509, 2006. 
52. Shalaeva DN, Dibrova DV, Galperin MY and Mulkidjanian AY: Modeling of interaction between cytochrome $\mathrm{c}$ and the WD domains of Apaf-1: Bifurcated salt bridges underlying apoptosome assembly. Biol Direct 10: 29, 2015.

53. Olichon A, Baricault L, Gas N, Guillou E, Valette A, Belenguer P and Lenaers G: Loss of OPA1 perturbates the mitochondrial inner membrane structure and integrity, leading to cytochrome c release and apoptosis. J Biol Chem 278: 7743-7746, 2003.

54. VaranitaT,SorianoME,RomanelloV,ZagliaT,Quintana-Cabrera R, Semenzato M, Menabò R, Costa V, Civiletto G, Pesce P, et al: The OPA1-dependent mitochondrial cristae remodeling pathway controls atrophic, apoptotic, and ischemic tissue damage. Cell Metab 21: 834-844, 2015.

55. Zhang L, He Z, Zhang Q, Wu Y, Yang X, Niu W, Hu Y and Jia J: Exercise pretreatment promotes mitochondrial dynamic protein OPA1 expression after cerebral ischemia in rats. Int J Mol Sci 15: 4453-4463, 2014.

56. Williams PA, Morgan JE and Votruba M: Opa1 deficiency in a mouse model of dominant optic atrophy leads to retinal ganglion cell dendropathy. Brain 133: 2942-2951, 2010.

57. Hu X, Dai Y, Zhang R, Shang K and Sun X: Overexpression of optic atrophy type 1 protects retinal ganglion cells and upregulates Parkin expression in experimental glaucoma. Front Mol Neurosci 11: 350, 2018.

58. Jardim FR, de Rossi FT, Nascimento MX, da Silva Barros RG Borges PA, Prescilio IC and de Oliveira MR: Resveratrol and brain mitochondria: A review. Mol Neurobiol 55: 2085-2101, 2018.

59. de Oliveira MR, Nabavi SF, Manayi A, Daglia M, Hajheydari Z and Nabavi SM: Resveratrol and the mitochondria: From triggering the intrinsic apoptotic pathway to inducing mitochondrial biogenesis, a mechanistic view. Biochim Biophys Acta 1860: 727-745, 2016.

60. Peng K, Tao Y, Zhang J, Wang J, Ye F, Dan G, Zhao Y, Cai Y, Zhao J, Wu Q, et al: Resveratrol regulates mitochondrial biogenesis and fission/fusion to attenuate rotenone-induced neurotoxicity. Oxid Med Cell Longev 2016: 6705621, 2016.

61. Lee H, Smith SB, Sheu SS and Yoon Y: The short variant of optic atrophy 1 (OPA1) improves cell survival under oxidative stress. J Biol Chem 295: 6543-6560, 2020.

62. MacVicar T and Langer T: OPA1 processing in cell death and disease-the long and short of it. J Cell Sci 129: 2297-2306, 2016.

63. Lang A, Anand R, Altinoluk-Hambüchen S, Ezzahoini H, Stefanski A, Iram A, Bergmann L, Urbach J, Böhler P, Hänsel J, et al: SIRT4 interacts with OPA1 and regulates mitochondrial quality control and mitophagy. Aging (Albany NY) 9: 2163-2189, 2017.

64. Alavi MV: Targeted OMA1 therapies for cancer. Int J Cancer 145: 2330-2341, 2019

65. Ishihara N, Fujita Y, Oka T and Mihara K: Regulation of mitochondrial morphology through proteolytic cleavage of OPA1. EMBO J 25: 2966-2977, 2006.

66. Song Z, Chen H, Fiket M, Alexander C and Chan DC: OPA1 processing controls mitochondrial fusion and is regulated by mRNA splicing, membrane potential, and Yme1L. J Cell Biol 178: 749-755, 2007.

67. Rainbolt TK, Lebeau J, Puchades C and Wiseman RL: Reciprocal degradation of YME1L and OMA1 adapts mitochondrial proteolytic activity during stress. Cell Rep 14: 2041-2049, 2016.
68. Stiburek L, Cesnekova J, Kostkova O, Fornuskova D, Vinsova K, Wenchich L, Houstek J and Zeman J: YME1L controls the accumulation of respiratory chain subunits and is required for apoptotic resistance, cristae morphogenesis, and cell proliferation. Mol Biol Cell 23: 1010-1023, 2012.

69. Rainbolt TK, Saunders JM and Wiseman RL: YME1L degradation reduces mitochondrial proteolytic capacity during oxidative stress. EMBO Rep 16: 97-106, 2015.

70. Singh LN, Crowston JG, Lopez Sanchez MIG, Van Bergen NJ, Kearns LS, Hewitt AW, Yazar S, Mackey DA, Wallace DC and Trounce IA: Mitochondrial DNA variation and disease susceptibility in primary open-angle glaucoma. Invest Ophthalmol Vis Sci 59: 4598-4602, 2018.

71. Kumar M, Tanwar M, Faiq MA, Pani J, Shamsi MB, Dada T and Dada R: Mitochondrial DNA nucleotide changes in primary congenital glaucoma patients. Mol Vis 19: 220-230, 2013.

72. Garcia I, Innis-Whitehouse W, Lopez A, Keniry M and Gilkerson R: Oxidative insults disrupt OPA1-mediated mitochondrial dynamics in cultured mammalian cells. Redox Rep 23: 160-167, 2018.

73. Kondadi AK, Anand R and Reichert AS: Functional interplay between cristae biogenesis, mitochondrial dynamics and mitochondrial DNA integrity. Int J Mol Sci 20: 4311, 2019.

74. Chen S, Fan Q, Li A, Liao D, Ge J, Laties AM and Zhang X: Dynamic mobilization of PGC- $1 \alpha$ mediates mitochondrial biogenesis for the protection of RGC-5 cells by resveratrol during serum deprivation. Apoptosis 18: 786-799, 2013.

75. Kim MJ, Chi BH, Yoo JJ, Ju YM, Whang YM and Chang IH: Structure establishment of three-dimensional (3D) cell culture printing model for bladder cancer. PLoS One 14: e223689, 2019.

76. Liang T, Tao Q, Guan R, Cao G, Shen H, Liu Z and Xia Q: Antioxidant and antiproliferative activities of cyanidin-3-O-glucoside $(\mathrm{C} 3 \mathrm{G})$ liposome in Caco-2 cells cultivated in 2D and 3D cell culture models. J Food Sci 84: 1638-1645, 2019.

77. Burd A, Kwok CH, Hung SC, Chan HS, Gu H, Lam WK and Huang L: A comparative study of the cytotoxicity of silver-based dressings in monolayer cell, tissue explant, and animal models. Wound Repair Regen 15: 94-104, 2007.

78. Li D, Ni S, Miao KS and Zhuang C: PI3K/Akt and caspase pathways mediate oxidative stress-induced chondrocyte apoptosis. Cell Stress Chaperones 24: 195-202, 2019.

79. Fukai T and Ushio-Fukai M: Superoxide dismutases: Role in redox signaling, vascular function, and diseases. Antioxid Redox Signal 15: 1583-1606, 2011.

80. Chen WM, Shaw LH, Chang PJ, Tung SY, Chang TS, Shen CH, Hsieh YY and Wei KL: Hepatoprotective effect of resveratrol against ethanol-induced oxidative stress through induction of superoxide dismutase in vivo and in vitro. Exp Ther Med 11: 1231-1238, 2016

81. Tomé-Carneiro J, Larrosa M, González-Sarrías A, Tomás-Barberán FA, García-Conesa MT and Espín JC: Resveratrol and clinical trials: The crossroad from in vitro studies to human evidence. Curr Pharm Des 19: 6064-6093, 2013.

This work is licensed under a Creative Commons Attribution-NonCommercial-NoDerivatives 4.0 International (CC BY-NC-ND 4.0) License. 